\title{
Towards a rigorous species delimitation framework for scleractinian corals based on RAD sequencing: the case study of Leptastrea from the Indo-Pacific
}

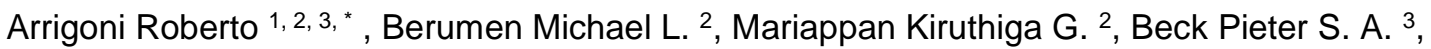 \\ Hulver Ann Marie ${ }^{2}$, Montano Simone ${ }^{4,5}$, Pichon Michel ${ }^{6}$, Strona Giovanni ${ }^{7}$, Terraneo Tullia Isotta ${ }^{2,8}$, \\ Benzoni Francesca ${ }^{2}$
}

1 Department of Biology and Evolution of Marine Organisms (BEOM), Stazione Zoologica Anton Dohrn Napoli, Villa Comunale, 80121, Naples, Italy

2 Red Sea Research Center, Division of Biological and Environmental Science and Engineering, King

Abdullah University of Science and Technology, Thuwal, 23955-6900, Saudi Arabia

${ }^{3}$ European Commission, Joint Research Centre (JRC), Ispra, Italy

4 Dipartimento Di Scienze Dell'Ambiente E del Territorio, Università Degli Studi Di Milano-Bicocca,

Piazza della Scienza 1, 20126, Milan, Italy

${ }^{5}$ Marine Research and High Education Center, Magoodhoo Island, Faafu Atoll, Maldives

${ }^{6}$ Queensland Museum, Biodiversity and Geosciences, Townsville, QLD, 4810, Australia

${ }^{7}$ Research Centre for Ecological Change, University of Finland, 00014, Helsinki, Finland

${ }^{8}$ ARC Centre of Excellence for Coral Reef Studies, James Cook University, Townsville, QLD, 4810,

Australia

* Corresponding author : Roberto Arrigoni, email address : roberto.arrigoni@szn.it

\begin{abstract}
:
Accurate delimitation of species and their relationships is a fundamental issue in evolutionary biology and taxonomy and provides essential implications for conservation management. Scleractinian corals are difficult to identify because of their ecophenotypic and geographic variation and their morphological plasticity. Furthermore, phylogenies based on traditional loci are often unresolved at the species level because of uninformative loci. Here, we attempted to resolve these issues and proposed a consistent species definition method for corals by applying the genome-wide technique Restriction-site Associated DNA sequencing (RADseq) to investigate phylogenetic relationships and species delimitation within the genus Leptastrea. We collected 77 colonies from nine localities of the Indo-Pacific and subjected them to genomic analyses. Based on de novo clustering, we obtained 44,162 SNPs (3701 loci) from the holobiont dataset and 62,728 SNPs (9573 loci) from the reads that map to coral transcriptome to reconstruct a robust phylogenetic hypothesis of the genus. Moreover, nearly complete mitochondrial genomes and ribosomal DNA arrays were retrieved by reference mapping. We combined concatenation-based phylogenetic analyses with coalescent-based species tree and species delimitation methods. Phylogenies suggest the presence of six distinct species, three corresponding to known taxa, namely Leptastrea bottae, Leptastrea inaequalis, Leptastrea transversa, one characterized by a remarkable skeletal variability encompassing the typical morphologies of Leptastrea purpurea and Leptastrea pruinosa, and
\end{abstract}


two distinct and currently undescribed species. Therefore, based on the combination of genomic, morphological, morphometric, and distributional data, we herein described Leptastrea gibbosa sp. n. from the Pacific Ocean and Leptastrea magaloni sp. n. from the southwestern Indian Ocean and formally considered L. pruinosa as a junior synonym of L. purpurea. Notably, mitogenomes and rDNA yielded a concordant yet less resolved phylogeny reconstruction compared to the ones based on SNPs. This aspect demonstrates the strength and utility of RADseq technology for disentangling species boundaries in closely related species and in a challenging group such as scleractinian corals.

Keywords : ezRAD, dDocent, Holobiont, SNAPP, Bayes factor delimitation, Morphometrics, New species 


\section{Introduction}

Scleractinian corals represent the major bioconstructors of tropical coral reefs, with millions of species living in closely association with them, and support economies of several countires (Knowlton 2001; Roberts et al. 2002). Nevertheless, they are threatened organisms given their rapid decline worldwide in response to numerous enthropogenic drivers both at local and global scales (Pratchett et al. 2017; Hughes et al. 2018, 2019). Considering this ongoing loss of coral diversity and the high extinction rate in marine habitats as we are transitioning in the Anthropocene era (McCauley et al. 2015; Hughes et al. 2017; Johnson et al. 2017), conservation strategies urgently call for accurate species assessments in characterizating coral biodiversity.

Coral species have been traditionally described using morphological traits of skeleton (Wells 1956; Chevalier 1975). Disagreements between conventional- and genetics-based systematics are common in all genera and have left the delineation of most extant species unresolved (Kitahara et al. 2016). From a molecular perspective, currently available markers are insufficient for species delimitation in the majority of genera (see for example Forsman et al. 2009; Terraneo et al. 2016). Mitochondrial barcoding genes of Anthozoa exhibit a slow evolutionary rate (Shearer et al. 2002; Hellberg 2006) while the nuclear ITS marker poses problems as it displays elevated intraindividual and 

morphological point of view, environment-induced phenotypic plasticity (Todd 2008; Paz-García et al. 2015) and genotype-driven intraspecific morphological variation (Carlon and Budd 2002; Dimond et al. 2017) have contributed to the taxonomic uncertainties. Furthermore, evolutionary convergence, morphological stasis, and homoplasy occur

61 in several traditional skeletal traits (Fukami et al. 2008; Flot et al. 2011; Arrigoni et al. 2016a, 2019).

The advent of high-throughput sequencing technologies provides an unprecedented chance to access a huge amount of genomic information and to resolve controversial phylogenetic relationships in great depth and all taxonomic levels (Metzker 2010). This is particularly true for Restriction-site associated DNA sequencing (RADseq; Miller et al. 2007; Baird et al. 2008), a reduced-genome technique that can be applied to non-model organisms for which there are no reference genome data available (Davey and Blaxter 2010). This approach relies on the sequencing of short DNA fragments flanking restriction sites, generating hundreds to thousands of random, unlinked, and homologous genomic loci, and single nucleotide polymorphisms (SNPs) (Andrews et al. 2016). Typically, RADseq has been used to establish phylogenetic relationships between closely related species and populations (Rubin et al. 2012; Ceballos et al. 2019). Nevertheless, its application has been successfully extended from shallow timescales also to divergences dating back to 50-60 Ma (Cariou et al. 2013; Eaton et al. 2017).

In this work, the scleractinian genus Leptastrea Milne Edwards and Haime, 1849, actually transferred to Incertae Sedis at the family level (Budd et al. 2012), is selected as case study to propose a rigorous integrative method to infer evolutionary relationships and delimitation of species within hard corals. Leptastrea is widely distributed throughout the Indian and central Pacific Ocean, where it is a common element of shallow reefs (Veron 2000). The genus currently includes seven colonial and zooxanthellate extant nominal species (Hoeksema and Cairns 2019), namely L. aequalis Veron, 2000, L. bewickensis Veron, Pichon and Best, 1977, L. bottae (Milne Edwards and Haime, 1849), L. inaequalis Klunzinger, 1879, L. purpurea (Dana, 1846), L. pruinosa Crossland, 1952, and L. transversa Klunzinger, 1879. According to the distribution maps in Veron (2000), they are widely distributed from the Red Sea to the central Pacific with the exception of $L$. bewickensis spanning from the eastern Indian to the Central Pacific. Species ascribed to Leptastrea have been described exclusively based on size and shape of skeletal structures (Matthai 1914; Chevalier 1975; Scheer and Pillai 1983). Nevertheless, remarkable morphological variation of the skeleton was described for species such as L. bottae, L. purpurea, and L. transversa from distinct habitats or different localities of the IndoPacific (Matthai 1914; Chevalier 1975; Veron et al. 1977; Scheer and Pillai 1983). Such variability has led to the 
complex synonymy history of, for example, L. purpurea with several nominal species described starting from the 19th century and now considered its junior synonyms (Milne Edwards and Haime1849; Verrill 1867; Hoeksema and Cairns 2019). Moreover, some species can be superficially so similar that taxonomists have hesitated to tell them apart, e.g. L. purpurea with L. transversa and L. purpurea with L. pruinosa (Vaughan 1918; Scheer and Pillai 1974; Veron et al. 1977). Due to the challenges of its species morphological identification, and the resulting taxonomic uncertainty, Leptastrea provides a good case study to address evolutionary and systematics issues in scleractinians. It has, however, remained poorly studied without any genetic analyses aimed to clarify species boundaries carried out so far (Fukami et al. 2008; Arrigoni et al. 2012). Therefore, Leptastrea is an ideal model to test general questions that are frequently applied to most phylogenetic studies on corals: (a) how can we distinguish closely related and morphologically similar species?; (b) which morphological characters are diagnostic of the independently evolving molecular lineages (i.e. species)?; (c) what is the actual species geographic distribution?

Herein, we applied a genome-scale ezRAD framework (Toonen et al. 2013) to elucidate the phylogenetic relationships and species delimitation in Leptastrea, using one of the largest coral genomic datasets published so far from a large geographic range spanning the whole Indo-Pacific. We newly sequenced and assembled three phylogenomic datasets: (a) 9,573 loci from the coral dataset by mapping reads to coral transcriptome reference; (b) 3,701 anonymous loci from the holobiont dataset (a close association of a diverse variety of organisms including coral, obligate symbiotic dinoflagellate algae, bacteria, fungi, and microbes, see Forsman et al. 2017) based on de novo assembly; (c) nearly complete mitochondrial genomes and ribosomal DNA arrays, including the barcoding region of the cytochrome oxidase subunit I gene and the ITS1 and ITS2 regions traditionally used in coral phylogenetic work, respectively. Phylogenomic information was then combined with morphological, morphometric, and geographical data to propose species delineation of Leptastrea in an integrative taxonomic context arising from multiple lines of evidence.

\section{Materials and methods}

\section{Sampling and identification}

A total of 77 Leptastrea colonies were sampled while SCUBA diving between 1 and $35 \mathrm{~m}$ depth at nine IndoPacific localities, namely Saudi Arabia (Red Sea coast), Djibouti, Yemen (Gulf of Aden coast and Socotra Island), Madagascar, Mayotte Island, the Maldives, Papua New Guinea, New Caledonia, and French Polynesia (Data S1). Two 
Lobactis scutaria (Lamarck, 1801) from the Red Sea were used as outgroup because this species is phylogenetically

114 closely related to Leptastrea (Fukami et al. 2008; Arrigoni et al. 2012) and its transcriptome is available (Kitchen et

115 al. 2015). Digital images of living corals were taken in the field with a Canon Powershot G9 in an Ikelite underwater

116 housing system. Samples were broken off from the colonies with hammer and chisel. A small fragment of each sample

117 was then preserved in $96 \%$ ethanol or CHAOS solution (not an acronym; 4 M guanidine thiocyanate, $0.1 \% \mathrm{~N}-$ lauroyl sarcosine sodium, $10 \mathrm{mM}$ Tris pH 8,0.1 M 2-mercaptoethanol) (Sargent et al. 1986) for molecular analyses. The remaining portion of the corallum was immersed in sodium hypochlorite for 48 hours to remove all soft parts, rinsed in freshwater, and dried for identification and microscope observation. Material sampled for this study was deposited at King Abdullah University of Science and Technology (KAUST, Kingdom of Saudi Arabia), University of MilanoBicocca (UNIMIB, Italy), Institut de Recherche pour le Développement (IRD, New Caledonia), James Cook University (JCU, Australia), and the Muséum National d'Historie Naturelle (MNHN, France). Specimens were identified to species based on skeleton morphology following Milne Edwards and Haime (1849), Klunzinger (1879), Crossland (1952), Veron et al. (1977), and Veron (2000) as well as referring to illustrations of holotypes in their original descriptions. Moreover, the type specimens of L. bottae, L. inaequalis, L. purpurea, and L. transversa and were examined (Figs. 1a, e, i, m, q) (Data S2).

\section{DNA extraction, ezRAD library preparation, and sequencing}

Total DNA was extracted using DNeasy ${ }^{\circledR}$ Blood and Tissue kit (Qiagen Inc., Hilden, Germany) for coral fragments preserved in ethanol or through a phenol-chloroform based method for samples in CHAOS. A Qubit ${ }^{\circledR}$ Fluorometer 3.0 (Thermo Fisher Scientific Inc., Waltham, MA, USA) was used to check that each DNA extract contained a minimum of 1.2-1.3 $\mu \mathrm{g}$ of genomic DNA. We followed protocols by Toonen et al. (2013) and Knapp et al. (2016) for DNA digestion and ezRAD library preparation. Each sample was digested using frequent cutter restriction enzymes MboI and Sau3AI (New England BioLabs, Ipswich, MA, USA) to cleave sequences at GATC cut sites (Toonen et al. 2013). All ezRAD libraries were obtained using TruSeq Nano DNA HT Library Prep Kit (Illumina, San Diego, CA, USA), size selected at 350 bp, ligated with a unique combination of Illumina adapters D701-D712 and D501-D508, normalized, and combined to two pools of 40 and 39 libraries, respectively. Each library pool was run in a single 150 bp paired-end lane on Illumina HiSeq 4000 System at KAUST Genomics Core Lab (Thuwal, 
Kingdom of Saudi Arabia). The sequenced lengths, number of reads, and sample information for each library are presented in Data S1.

\section{ezRAD data processing}

The Illumina raw data consisted of 509,354,215 million 150 bp reads for all 77 samples. All samples were demultiplexed using their unique barcode and adapter sequences under the Illumina pipeline bcl2fastq/2.17.1.14 (with no mismatches allowed for the barcode), effectively removing reads that lacked identifiable barcode pairs. All samples were trimmed for low quality base-pairs and adapter sequences using Trimmomatic v.0.36 under the default parameters (Bolger et al. 2014). The ezRAD analysis was performed twice, first as a holobiont and after assembling the reads to the L. scutaria transcriptome.

To perform the holobiont analysis, the dDocent 2.2.25 pipeline mentioned in Puritz et al. (2014) was followed under the default parameters unless indicated here. Total reads were placed in a folder as *.F.fq.gz and *.R.fq.gz and trimmed reads were placed as *.R1.fq.gz and *.R2.fq.gz, respectively. About 5.9 million trimmed reads per sample were obtained. Briefly, the dDocent v.2.2.25 pipeline (Puritz et al. 2014) was started merging the trimmed reads using PEAR v.0.9.6 (Zhang et al. 2013) and an assembly was created using BWA v.0.7.15 (Li and Durbin 2009) under the following options, t 16 -a -M -T $10-\mathrm{R}$. The bam files were then sorted and merged using SAMtools v.1.6 ( $\mathrm{Li}$ et al. 2009) to create one single bam file. Variants were called using FreeBayes (Garrison and Marth 2012) under the following options, -0 -E 3 -G 5 -z 0.1 -X -u -n 4 --min-coverage 5 --min-repeat-entropy 1 -V -b options. The postassembly dDocent 2.2.25 pipeline was done after aligning the trimmed reads to the transcriptome of L. scutaria using Bowtie v.2 2.3.4 (Langmead and Salzberg 2012), and the aligned reads were converted to fastq files using BEDTools v.2.26.0 (Quinlan and Hall 2010). These files were renamed as *F.fq.gz and *R.fq.gz and were placed along with the L. scutaria transcriptome as reference.fasta. dDocent 2.2.25 (Puritz et al. 2014) was initiated without the assembly option to create the reference fasta file and executed with the same options as mentioned above. SNPs were identified using FreeBayes (Garrison and Marth 2012) following Forsman et al. (2017).

One of the main benefits of ezRAD is that it ends up with both considerable vertical and horizontal coverages (as depth and breadth) (Terraneo et al. 2018a, 2018b; Stobie et al. 2019). While the former is used to call SNPs, the latter generates very long contigs, resulting in the resolution of the complete or a large percentage of the mitochondrial genomes and other multicopy gene regions such as ribosomes. Reference mapping against previously published 
reference sequences of mitochondrial genome (mitogenome) and nuclear ribosomal DNA (rDNA, including the complete $18 \mathrm{~S}$, ITS1, 5.8S, ITS2, and $28 \mathrm{~S}$ regions) was carried out to acquire and compare nearly complete mitogenomes and rDNA from each library. As reference, we used the complete mitochondrial genome of Polycyathus chaishanensis Lin et al. 2012 (JF825140) and the nearly complete rDNA of L. purpurea (LT631161, HE648522, JQ966138). Raw de-multiplexed reads were trimmed for adapters and low-quality bps using Trimmomatic v.0.36 (Bolger et al. 2014). Trimmed reads were aligned to the reference sequences using Bowtie v.2 2.3.4 (Langmead and Salzberg 2012) in --fast-local mode. Aligned reads were convert to bam and indexed using SAMtools v.1.6 (Li et al. 2009), and the consensus sequences were identified using SAMtools mpileup combined with Vcfutils.pl.

\section{Phylogenomic analyses}

The resulting vef files from both the coral and holobiont datasets were further filtered using VCFtools v.0.1.16 (Danecek et al. 2011). To examine the sensitivity of the phylogenetic inference to the filtering process, we generated two filtered supermatrices for both the coral and holobiont datasets. In particular, following Forsman et al. (2017) we obtained the "coral-max" and the "holobiont-max" supermatrices using the following filter options: mean depth = 5, max missing data $=50 \%$, and minimum distance between SNPs $=10$. Conversely, we generated the "coral-min" and the "holobiont-min" supermatrices using the following filter options: mean depth $=10$, max missing data $=0 \%$, and minimum distance between SNPs $=300$. Haplotypes were then called and filtered for complex loci, potential paralogs, missing data, and sequencing errors using the rad_haplotyper v.1.1.8 pipeline (https://github.com/chollenbeck/rad_haplotyper; Willis et al. 2017). Contigs were then collapsed into genotypes for final analyses. PGDspider v.2.1.1.5 (Lischer and Excoffier 2011) was used to convert the dataset to the required file types for further analysis. The resulting four concatenation-based loci supermatrices were analyzed in RAxML v8.2.10 (Stamatakis 2014) for maximum likelihood (ML) phylogenetic inference. We applied the GTR + GAMMA substitution model for all the phylogenetic analyses, and the branch support was assessed by 500 rapid bootstrap replicates. The "coral-max" and "holobiont-max" supermatrices were also investigated by means of Bayesian Inference with BEAST v.2.5.2 (Bouckaert et al. 2014). The GTR + GAMMA substitution model and an uncorrelated (lognormal) clock model were applied. Chains were run for 100 million iterations, sampling every 50,000 iterations, and checked for stationarity and parameter effective sample sizes with Tracer v.1.7 (Rambaut et al. 2018). Final trees 
were built using the BEAST module TreeAnnotator v.2.5.2 (Bouckaert et al. 2014), discarding the first 10\% as burnin as indicated by Tracer v.1.7 (Rambaut et al. 2018).

The mitogenome and rDNA datasets were aligned using MAFFT v. 7 with the E-INS-i strategy (Katoh and Standley 2013). We determined the optimal among-gene partitioning scheme and model choice for dataset in PartitionFinder v.2 (Lanfear et al. 2016) under the Bayesian Information Criterion (BIC). The mitogenomes were partitioned according to the genes, considering all intergenic regions as a single partition, while genes were further partitioned according to the codon positions. The rDNA dataset was partitioned in five partitions, 18S, ITS1, 5.8S, ITS2, and 28S Phylogenetic relationships based on mitogenome and rDNA alignments were inferred using both ML and BI, under parameters and options applied for the "coral-max" and "holobiont-max" supermatrices. We also built ML phylogenetic trees based on two barcoding loci traditionally and widely used for scleractinian corals (Kitahara et al. 2016), namely a portion of the cytochrome oxidase subunit I gene of the mitochondrial genome (COI) and the complete ITS1, 5.8S, and ITS2 regions of the rDNA (ITS). Lobactis scutaria was selected as outgroup for all the phylogenetic analyses following Arrigoni et al. (2012). All ML and BI analyses were run on the CIPRES Science Gateway (Miller et al. 2010).

\section{Species delimitation analyses}

Bayes Factor Delimitation with genomic data (BFD*) was used to test eight reasonably possible species delimitation models (Leaché et al. 2014). In particular, we considered the following models: (1) one single species; (2) current taxonomy, distinguishing L. bottae, L. inaequalis, L. pruinosa, L. purpurea, L. transversa, and the undescribed morph from Madagascar and Mayotte (six species); (3) current taxonomy but lumping L. purpurea with L. transversa (five species); (4) current taxonomy but lumping $L$. purpurea with $L$. pruinosa and $L$. transversa (four species); (5) groups resulting from ezRAD phylogenies including the undescribed morph from Madagascar and Mayotte and $L$. cf bottae from New Caledonia and Papua New Guinea (six species); (6) proposed ezRAD phylogenies but splitting $L$. purpurea and L pruinosa (seven species); (7) proposed ezRAD phylogenies but lumping L. purpurea with $L$ pruinosa and $L$. transversa (five species); (8) proposed mitogenome and rDNA phylogenies (five species). In order to reduce computational time, we sampled three individuals per species. We used VCFtools v.0.1.16 (Danecek et al. 2011) to generate a supermatrix of 21 individuals, including only unlinked biallelic SNPs with $0 \%$ missing data as required by SNAPP. The SNAPP package (Bryant et al. 2012) implemented in BEAST v.2.5.2 (Bouckaert et al. 
2014) was used to run a path sampling method with 48 steps, each one consisting of 100,000 MCMC generations saving every 1000 generations with a pre-burnin of 10,000 steps. Model convergence was assessed using Tracer v.1.7 (Rambaut et al. 2018). We compared and ranked models to select the best-supported species hypothesis by using the estimated marginal likelihood (MLE) of each model and by calculating the Bayes factor (BF) as (2* [modell model2]) (Kass and Raftery 1995).

The species tree analysis was based on the results of BFD* runs described above, using the best supported model. A coalescent-based species tree was obtained by using the SNAPP package (Bryant et al. 2012) implemented in BEAST v.2.5.2 (Bouckaert et al. 2014). In order to reduce the complexity in species tree estimation and increase parameter convergence probability, we sampled two individuals per species since calculations do not benefit from adding extra individuals over number of loci (Drummond and Bouckaert 2015). We used VCFtools v.0.1.16 (Danecek et al. 2011) to generate a supermatrix of 12 individuals, including only unlinked biallelic SNPs with 0\% missing data as required by SNAPP. The analysis run for 10 million MCMC generations, sampling every 1000 steps, with mutation rate and priors estimated during the chains, and all the other settings set as default. The convergence of the analysis was checked using Tracer v.1.7 (Rambaut et al. 2018) and, as suggested by the software, we discarded the first 10\% of trees as burn-in. We analyzed the tree files with SNAPP-TreeSetAnalyser v.2.5.2 to identify species trees that are contained in the $95 \%$ highest posterior density (HPD) set and using $10 \%$ of topologies as burn-in. Densitree v.2.5.2 (Bouckaert 2010) was used to visualize the posterior distributions of topologies as cladograms, hence allowing for a clear depiction of uncertainty in the topology.

\section{Morphological and morphometric analyses}

Macro and micromorphological observations of coral skeletons were performed using light microscopy and scanning electron microscopy (SEM), respectively. Images of the coralla with a reference scale were taken with a Canon G15 digital camera and through a Leica M205 FA stereo-microscope at fixed magnifications. A collection of skeleton images was obtained for each of the examined specimens and of the type specimens. Measurements were done with the ImageJ Analyse tool (Rueden et al. 2017; https://imagej.nih.gov/ij/) from images at known magnification. Six characters on each of five corallites were measured for each specimen: (v1) maximum calice diameter; (v2) minimum calice diameter; (v3) maximum columella diameter; (v4) minimum columella diameter perpendicular to $\vee 3$; (v5) distance between the centre of the columella and the centre of the columella of the closest 
adjacent corallite; (v6) width of the groove among the corallites. A principal component analysis (PCA) was conducted on averaged measures per specimen for the six variables using the PRIMER v.7.0.13 statistical package (Primer-e).

For SEM imaging, fragments of coral specimens were ground, mounted on stubs using silver glue and sputter coated with gold, and examined with a Vega Tescan Scanning Electron Microscope at the SEM Laboratory (UNIMIB). Imaging was conducted to describe and illustrate the following skeletal features of each species for comparative purposes: radial elements relative thickness, height and ornamentation (margin and sides), septal fusion pattern among cycles and with the columella, structure and shape of the columella.

For a glossary of skeletal terms, we followed Budd et al. (2012) and Huang et al. (2014).

\section{Geographic distribution analyses}

Occurrence data plotted to obtain species distribution maps came from two different sources: (a) material collected and analyzed from a genomic and morphological point of view for this study (Data S1); (b) specimens with reliable sampling locality information deposited in museum collections housed at the MNHN, National Museum of Natural History, Smithsonian Institution (NMNH, USA), Natural History Musem, London (NHM, the U.K.), the Museum für Naturkunde, Berlin (ZMB, Germany), and the Museum of Tropical Queensland, Townsville (MTQ, Australia) (Taxonomic Account and Data S2). The reliability and objectivity of the latter source were based on the diagnostic morphological characters that we summarized in the nomenclature acts.

To ease the visual identification of large scale biogeographical patterns, and particularly the degree of overlap in species distributions, we used species occurrences to derive geographical ranges for the six coral species using the $\alpha$ hull procedure (García-Roselló et al. 2015). To select a proper value for the a parameter (that is, ensuring a conservative estimation of species ranges), we started with a very small $\alpha(0.001)$, and then we incremented it progressively in small amounts (0.005), and then largest $\alpha$ value for which all occurrences where included in the resulting range.

\section{Results}

The Leptastrea colonies sampled for this study belong to five morpho-species currently considered valid (Hoeksema and Cairns 2019), namely the genus type species L. purpurea (n=29) (Fig. 1a-d, Fig. S1_1), L. pruinosa $(\mathrm{n}=3)$ (Fig. 1e-h), L. transversa (19) (Fig. 1i-1, Fig. S1_2), L. bottae (n=6) (Fig. 1m-p, Fig. S1_3), and L. inaequalis 
$(\mathrm{n}=9)$ (Fig. 1q-t, Fig. S1_4). Plocoid specimens with barrel-shaped corallites and distinctive coenosteum grooves from New Caledonia and Papua New Guinea match the east Australian material identified as L. cf bottae ( $\mathrm{n}=5$ ) by Veron et al. (1977: Figs 300-302) (Fig. 2, Fig. S1_5). A distinctly plocoid morph of Leptastrea collected from Mayotte Island and north Madagascar $(n=6)$ does not match any of the existing species descriptions (Fig. 3, Fig. S1_6). Hereafter, we use the name L. gibbosa sp. n. for the specimens preliminary identified as L. cf bottae sensu Veron et al. (1977), and L. magaloni sp. $\mathrm{n}$. for the distinct undescribed morph of Leptastrea collected from Madagascar and Mayotte. Both names are formally assigned based on genomic, morphological, and distributional evidence in the taxonomic section further in this paper. However, for the sake of clarity, they are used throughout the manuscript in order to avoid nomenclatural confusion.

\section{ezRAD phylogenomic inference}

The unfiltered holobiont dataset included a total of 8,323 contigs while the coral transcriptome itself had 101,322 contigs (= loci). Therefore, the chance of reads mapping and SNP detection was high in the binned case. At the end of the dDocent and rad_haplotyper pipeline, the "holobiont-max" supermatrix included 3,701 loci and a total of 44,162 SNPs, the "coral-max" supermatrix 9,573 loci and 62,728 SNPs, the "holobiont-min" supermatrix 2,075 loci and 2,141 SNPs, and the "coral-min" supermatrix 2,366 loci and 2,479 SNPs (all alignment data are available upon request to the corresponding author).

The phylogenetic trees inferred from the concatenated "holobiont-max" and "coral-max" matrices provided a fully resolved phylogeny of Leptastrea species (Fig. 4). They recovered the presence of six strongly supported clades, namely clade I (L. gibbosa sp. n.), clade II (L. purpurea and L. pruinosa), clade III (L. transversa), clade IV ( $L$. magaloni sp. n.), clade V (L. inaequalis), and clade VI (L. bottae). Leptastrea gibbosa sp. n. and L. magaloni sp. n. were reciprocally monophyletic with high support values in all analyses. Moreover, L. gibbosa sp. n., previously identified as L. cf bottae (Veron et al. 1977) or L. bottae (Veron 2000) based on the traditional morphology-based taxonomy, was clearly separated and distinct from the Indian representatives of $L$. bottae. The three samples matching the typical morphology of L. pruinosa from the Gambier Islands (French Polynesia) and New Caledonia were mixed with the many analyzed samples of L. purpurea from the Indo-Pacific, without any genomic distinction. The sister relationships between L. bottae and L. inaequalis, and between the lineage they constitute and L. magaloni sp. n. were found in both the phylogenetic trees with strong support values (Fig. 4). Notably, the topologies of the two phylogeny 
reconstructions were different because of the position of $L$. gibbosa sp. n., which was sister to $L$. transversa in the holobiont tree and sister to the lineage leading to L. magaloni sp. n., L. bottae, and L. inaequalis in the coral tree (Fig. 4).

The phylogenetic trees inferred from the concatenated "holobiont-min" and "coral-min" datasets (Fig. S2) were much less resolved, presenting low/very low bootstrap support compared to the ones obtained with more loci and more missing data. Nevertheless, the two phylogenetic analyses resolved, with generally low support values, four out of the six molecular clades found based on "holobiont-max" and "coral-max" matrices, including clade I (L. gibbosa sp. n.), clade II (L. purpurea and L. pruinosa), clade III (L. transversa), and clade IV (L. magaloni sp. n.). Conversely, representatives of the two closely related clades clade V (L. inaequalis) and clade VI (L. bottae) were mixed.

\section{Nearly complete mitogenome and rDNA phylogenetic inference}

Mapping reads to the mitochondrial reference genome of Polycyathus chaishanensis resulted in a mean of 2,539 reads, covering $91 \%$ of the reference sequence per library (Data S1). The mitogenome alignment was 10,837 bp long and revealed low divergence across samples, with $98 \%$ of the positions conserved, and only 214 variable sites of which 165 were parsimony-informative (Data S3). By excluding the two outgroup sequences, the alignment contained 140 variable positions of which 99 were parsimony-informative. Concerning the rDNA arrays, approximately 17,269 reads mapped to the rDNA reference sequences, with a mean of $83 \%$ of the reference sequence covered (Data S1). The rDNA multiple alignment consisted of $5,835 \mathrm{bp}$ and displayed low genetic variability across the samples, being conserved for $98.9 \%$ nucleotide positions, with a total of 66 variable bp of which 53 were parsimony-informative (Data S4). Considering only the ingroup, the variable positions decreased to 43 of which 38 were parsimonyinformative.

The phylogeny reconstructions based on mitogenomes and rDNA resolved clade I ( $L$. gibbosa sp. n.), clade II ( $L$. purpurea and L. pruinosa), clade III (L. transversa), and clade IV (L. magaloni sp. n.) (Fig. 5), although with weaker support values than the ones obtained from the phylogenetic trees inferred based on the holobiont and coral ezRAD data. Both mitogenomes and rDNA trees failed to recover clade V (L. inaequalis) and clade VI (L. bottae) as distinct lineages as samples of these two species grouped together in a single clade without genetic distinction. Both phylogenetic analyses placed L. magaloni sp. n. and the lineage including L. inaequalis and L. bottae as sister taxa, in agreement with the holobiont and coral ezRAD topologies. Moreover, L. transversa and clade II (L. purpurea and $L$. 
pruinosa) had a sister relationship in both trees. Similarly to the discordance described between the holobiont and coral ezRAD trees, the mitogenome and rDNA tree topologies differed in the placement of L. gibbosa sp. n. which was the basal species of Leptastrea according to the mitogenome whereas it was the sister taxon of the lineage leading to L. transversa and the clade with L. purpurea and L. pruinosa.

The phylogenetic trees based on the barcoding loci COI and ITS were mostly unresolved, generally displaying very low bootstrap support (Fig. S3). In particular, the phylogeny reconstruction inferred from COI resolved clade II (L. purpurea and L. pruinosa) with high support value (100) and clade I (L. gibbosa sp. n.) without any significant support values. All the samples from the remaining four clades identified by the ezRAD phylogenies were mixed and their relationships unresolved. The phylogenetic hypothesis based on ITS resolved clade II (L. purpurea and $L$. pruinosa) with medium support value (80) and clade I (L. gibbosa sp. n.) with low support value (56). Clade II ( $L$. transversa) was not monophyletic but its samples did not group with any other species. Samples of clade IV, V, and VI clustered together without any genetic structuring.

\section{Species delimitation analyses}

We tested eight species delimitation models with the BFD* method to identify the number of lineages in Leptastrea (Table 1). The best-supported model involved considering the six molecular clades (from I to VI) found in the ezRAD phylogenies as six distinct species (model $5, \mathrm{MLE}=-12,650.36, \mathrm{BF}=-$ ). The other seven models were ranked as follows: proposed EzRAD phylogenies but splitting L. purpurea and L. pruinosa (model 6, MLE = -12,659.39, BF= 18.06), proposed mitogenome and rDNA phylogenies (model $8, \mathrm{MLE}=-12,680.83, \mathrm{BF}=60.94$ ), current taxonomy (model 2, MLE = -13,128.18, BF= 955.64), proposed EzRAD phylogenies but lumping L. purpurea with L pruinosa and L. transversa (model 7, MLE $=-13,561.36, \mathrm{BF}=1,822$ ), current taxonomy but lumping L. purpurea with $L$. pruinosa and L. transversa (model 4, MLE $=-14,010.44, \mathrm{BF}=2,720.16$ ), current taxonomy but lumping L. purpurea with $L$ transversa $($ model 3, $\mathrm{MLE}=-14,015.65, \mathrm{BF}=2,730.58)$, one single species $($ model $1, \mathrm{MLE}=-15,329.96, \mathrm{BF}=$ 5,359.2). In summary, BFD* supported the findings of the two phylogeny reconstructions presented in Fig. 4.

The species tree was estimated based on 1,857 unlinked biallelic coral SNPs with $0 \%$ missing data (Fig. 6a). We followed the best-supported model from the BFD* analysis, i.e. considering the six molecular clades (from I to VI) found in the concatenation-based ezRAD phylogenies as six distinct species. Following the SNAPP- TreeSetAnalyser package, only one topology summarized the $95 \%$ HPD consensus tree. This was consistent with the topology of the 
concatenation-based tree inferred from the "holobiont-max" supermatrix. Two major groups, each of which was composed by three species, were resolved: the first clade recovered the sister relationship between $L$. bottae and $L$. inaequalis, which were sister to L. magaloni sp. n.; the second group supported the sister relationship between $L$. transversa and L. gibbosa sp. n., which were sister to L. purpurea. All the nodes received full support values with a Bayesian posterior probability of 1 , except the one referring to L. bottae and L. inaequalis, supported by 0.99 .

\section{Morphometric analyses}

A total of 74 Leptastrea colonies, including type specimens, were included in our morphometric analyses based on six variables (v1-v6) measured on each (5 replicates per variable). Mean values (st. dev.) and the number of colonies per species are provided in Data S5. Multivariate analysis of the skeletal variables per specimen dataset could separate specimens into five groups (Fig. 7) corresponding to L. transversa, L. bottae, L. inaequalis, L. gibbosa sp. n. and $L$. magaloni sp. n., thus matching the groupings obtained by genomic analyses. However, specimens of the morphologically variable L. purpurea (Fig. S4a-h) completely overlapped with L. magaloni sp. n. and partially with L. bottae along the first two PC of the PCA plot (Fig 7). The strongest correlations were between PC1 and the linear distance among centres of adjacent corallites $(v 5, r=0.66)$ and the maximum calice diameter $(v 1, r=0.63)$. Similarly, moderate positive correlations were recovered between initial variables and PC2, the stronger being with v4 (minimum columella diameter, $r=0.62)$ and v5 $(r=0.59)$. Gap width among corallites was observed and measured exclusively in specimens of L. gibbosa sp. n. and L. inaequalis. Despite the former having consistently smaller corallite and columella features than the latter (Data S5), the gaps width was similar in the two species.

\section{Geographic distribution analyses}

The newly obtained distribution maps of the six Leptastrea species are illustrated in Fig. 6b. Leptastrea purpurea and L. bottae exhibit a widespread and overlapping geographic distribution in the Indo-Pacific. Notably, the total number of occurrences for these two species considerably increased based on the information obtained from museum collections and the taxonomic literature. Leptastrea gibbosa sp. n. is distributed across Papua New Guinea, Australia, and New Caledonia. The remaining three species, i.e. L. bottae, L. inaequalis, and L. magaloni sp. n., display an Indian Ocean distribution with some distinctions. Leptastrea bottae appears to have a disjoint distribution, occurring in the seas around the Arabian Peninsula (Red Sea and the Gulf of Aden) and in the eastern Indian Ocean (Cocos Islands). 
Leptastrea inaequalis is found in the seas around the Arabian Peninsula and in the western-central Indian Ocean (Mayotte Island, Seychelles, Maldives, and Laccadive Sea). Leptastrea magaloni sp. n. is restricted to the southernwestern Indian Ocean (Mayotte Islands, Madagascar, and South Africa).

\section{Taxonomic Account}

Based on the results arising from genomic, morphological, and distributional data, we propose a revised taxonomy for the examined Leptastrea species. In particular, (a) L. gibbosa sp. n. and L. magaloni sp. n. are formally described; (b) L. pruinosa is considered a junior synonym of L. purpurea; (c) L. bottae and L. inaequalis geographic distributions are revised and they are now considered restricted to the Red Sea and Indian Ocean (Data S2).

\section{Order Scleractinia Bourne, 1900}

Family Incertae Sedis

Genus Leptastrea Milne Edwards and Haime, 1849

Synonyms: Bathyastrea Milne Edwards and Haime, 1849, Orbicella (Leptastraea) Milne Edwards and Haime, 1849 , Orbicella (Leptastrea) Milne Edwards and Haime, 1849.

Type species: Leptastrea roissyana Milne Edwards and Haime, 1849 (=Astrea purpurea Dana, 1846).

Species included: Leptastrea aequalis Veron, 2000, Leptastrea bewickensis Veron, Pichon and Best, 1977, Leptastrea bottae (Milne Edwards and Haime, 1849), Leptastrea gibbosa sp. n. Benzoni and Arrigoni, 2019, Leptastrea inaequalis Klunzinger, 1879, Leptastrea magaloni sp. n. Benzoni and Arrigoni, 2019, Leptastrea purpurea (Dana, 1846), Leptastrea transversa Klunzinger, 1879.

Leptastrea gibbosa sp. n. Benzoni and Arrigoni, 2020 (Fig. 2, Figs. S1_5, S4m-p)

Synonymy: Leptastrea bottae (Milne Edwards and Haime, 1849), Crossland 1952, Plate I, Fig. 4; Plate II, Fig. 3; Leptastrea bottai (Milne Edwards and Haime, 1849) Chevalier, 1975, Plate II, Figs. 8-9; Plate III, Fig. 5; Plate XXXVIII, Figs. 4-5, 11; Leptastrea cf bottae (Milne Edwards and Haime, 1849), Veron et al. 1977, Figs. 300-302, 466; Leptastrea inaequalis Nishihira and Veron 1995; Veron 2000, Figs. 3-6 and corallite image.

Etymology: Gibbosus, "humped" in Latin, refers to the uneven aspect of the colony surface caused by the protruding rounded corallites. 
419 Type material: MNHN-IK-2012-9822 Magic Pass, Madang, Papua New Guinea (5¹1.356' S; 14549.637' E), 420 MNHN NIUGINI Expedition, 11/11/2012 (coll. F. Benzoni: UNIMIB PFB082).

421 Other material examined: Australia: BM 1934.5.14.444 (GBR Expedition: n²407), 1934; MTQ: G68954 Elisabeth 422 and Middleton (coll. J.E.N. Veron); G68956 Yule Reef, Queensland, 02/11/1974 (coll. J.E.N. Veron \& M. Pichon); G68955 Middleton Reef, 05/12/1981 (coll. J.E.N. Veron); G36744 Jewell Reef, Queensland (14²3' S; $145^{\circ} 22$ 'E); G68957 Jewell Reef, Queensland (coll. J.E.N. Veron \& M. Pichon); G65509 Elisabeth Reef (2956' S; 159²' E), 2007 (coll. A. Noreen); G36748 Lizard Island, Queensland (1440' S; 145²7' E); G36750 Bowl Reef, Queensland (18³1' S; 147³2' E); G36745 Fantome Island, Palm Islands (1841' S; 146³1' E); G39298 Bullumbooroo Bay, Great Palm Islands (1843' S; 146³4' E); G36749 Hook Island, Whitsunday Islands (2004' S; $148^{\circ} 57^{\prime}$ E); G39297 Swain Reefs ( $\left.21^{\circ} 07^{\prime} \mathrm{S} ; 142^{\circ} 46^{\prime} \mathrm{E}\right)$; JCU AU519 Mellish Reef, Coral Sea (17²5.591' S; $155^{\circ} 51.196^{\prime}$ E), JCU Coral Sea Cruise, 15/12/2018 (coll. F. Benzoni); Papua New Guinea UNMIB PFB805 Kavieng (2³7.224' S; 150³1.750' E), 22/08/2014 (coll. F. Benzoni). New Caledonia: MNHN-IK-2016-10 (coll. J.-P. Chevalier: P152g1); MNHN-IK2016-9 (coll. J.-P. Chevalier: P152g2); MNHN unregistered Surprise Atoll, d'Entrecasteaux Reefs (coll. J.-P. Chevalier: SU14c); HS0330 Extérieur Grand Récif Tetembia, 02/02/1987 (coll. IRD-plongeur); IRD HS1678 Kouakoué ( $21^{\circ} 47.842^{\prime}$ S; $166^{\circ} 37.661^{\prime}$ E), CORALCAL1, 25/03/07 (coll. F. Benzoni \& G. Lasne); HS1681 ST1082 (2147.842' S; $166^{\circ} 37.661^{\prime}$ E), CORALCAL1, 25/03/07 (coll. F. Benzoni \& G. Lasne); HS1684 Kouakoué, Grande

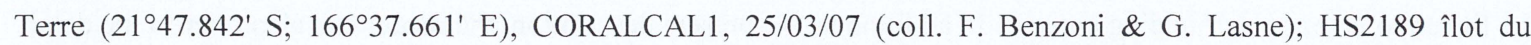
Mouillage, Chesterfield Islands (1947.191' S 158²7.519' E) CORALCAL2 19/07/08 (coll. G. Lasne \& J. Butscher); HS2344 Belep Island, Great North Lagoon (19³2.182' S 163³4.380' E), CORALCAL3, 15/03/09 (coll. G. Lasne \& J. Butscher); HS2460 Cook Reef, Great North Lagoon (1902.989' S 163³8.857' E), CORALCAL3, 21/03/09 (coll. G. Lasne \& J. Butscher); HS3167 Moneo, Grande Terre (2103.354' S; 165³5.297' E), CORALCAL4; HS3653 UatéOro Bay, Isle of Pines (22³5.2' S; 167³1.73' E), CORALCAL5, 01/10/2015 (coll. F. Benzoni); HS3740 Kuto, Isle of Pines (22³9.101' S; 167²1.154' E), CORALCAL5, 05/10/2015 (coll. F. Benzoni).

Description: Corallum encrusting to submassive (Fig. 2a-c, Fig. S1_5), circular to irregular in outline, rarely exceeding $15 \mathrm{~cm}$ in diameter. Budding extracalicular. Corallites can be evenly arranged on the corallum surface or variably exsert and inclined, both arrangements can occur in different parts of the same colony (Fig. S1_5). Among the corallites, $0.4 \mathrm{~mm}$ wide $( \pm 0.1 \mathrm{~s}$.d.) grooves and pits alternate with an irregularly developed coenosteum (Fig. 2ae, g, Fig. S4m-p). Longitudinal sections of the coralla show that this is composed of distinct solid beam-like structures 

structures have been called verrues (warts, in French) by Chevalier (1975: 56) and beams (Crossland 1952: 116) in descriptions of material we examined and that is here ascribed to Leptastrea gibbosa sp. n.. As shown also in the skeleton histological sections by Chevalier (1975: Fig. 26), the beams result from the fusion of processes laterally developing from, and all along, the outer wall of adjacent corallites (Fig. 2f). Calice outline mainly circular, average maximum diameter $1.6 \mathrm{~mm}( \pm 0.2$ s.d.) and minimum diameter $1.3 \mathrm{~mm}$ ( \pm 0.1 s.d.) (Fig. $2 \mathrm{~g})$. Corallite outline circular to irregularly polygonal with rounded corners (Fig. $2 \mathrm{~d}-\mathrm{e}, \mathrm{g}$ ). Two complete and one incomplete cycles of radial elements are present (Fig. 2i). S1 reaches the columella, its septa typically exsert from the colony surface (Fig. 2h) and with a slightly undulating upper margin (Fig. 21). S2, of variable length, shorter and less exsert than S1. S3 incomplete and very reduced (Fig. 2i-j). Septal sides irregularly covered in well-spaced pointed ornamentations (Fig. 21). Beyond the corallite wall, radial elements are clearly distinguishable, tightly packed and finely granulated (Fig. 2j). Columella formed by mostly fused trabecular processes and forming granulations at their upper end (Fig. 2i-k), $0.6 \mathrm{~mm}( \pm 0.1$ s.d.) in maximum diameter. A giant corallite can form in some coralla (Fig. 2b, Fig. S4p; Crossland 1952: 116, Plate II, Fig. 3; Veron et al 1977: 156, Figs. 301, 158). This is usually twice as large as the others in the same colony and more exert (Fig. S4p). It contains up to 4 complete cycles of septa with both S1 and S2 reaching the columella formed by multiple trabecular processes and fusing with it. These odd oversized corallites do not seem to be linked to an ongoing budding process. In addition to the present description, the reader can also refer to the detail treatment of specimens P152g2 (MNHN-IK-2016-9) and SU14c (MNHN unregistered) in Chevalier (1975: 57-58). Polyps of Leptastrea gibbosa sp. n. have a rather consistent brown colouration and their tentacles are usually retracted at daytime (Fig. S1_5). The tissue covering the outer part of the corallites and the coenosteum is yellowish to light green, becoming almost transparent in parts where corallites are more exsert or irregularly arranged (Fig. S1_5f, g). This species was most often encountered on the upper part of the reef slope between 2 and $15 \mathrm{~m}$ in well-lit environments.

470 Molecular phylogeny: Recovered as a monophyletic lineage (clade I) with high node support values in all 471 phylogenetic trees presented in this study (Figs. 4-5). This species is clearly genomically distinct from L. inaequalis 472 (clade V) and L. bottae (clade VI). Although the phylogenetic placement of the species is unstable across the phylogenetic analyses, the species tree indicates that the species is sister to L. transversa (Fig. 6a). 
Remarks: This species has been referred to as L. inaequalis, L. bottae and/or L. cf bottae (Crossland 1952; Veron et al. 1977; Nishihira and Veron 1995; Veron 2000). This confusion likely stems from the fact that both L. inaequalis and L. bottae share with L. gibbosa sp. n. a typically circular calice outline (Figs. 1m-o, q-s). Moreover, the irregular corallite arrangement and formation of grooves and pits described above for L. gibbosa sp. n. are also observed in $L$. inaequalis (Figs. 1q-s, Fig. S4q-t), and the gaps among corallites have similar dimensions in both species (Data S5). However, L. gibbosa sp. n. is distinguished from both L. inaequalis and L. bottae based on its smaller calice and columella dimensions (Data S5) and the presence of 2 rather than 3 complete cycles of septa. Finally, L. gibbosa sp. n. is restricted to the Pacific Ocean whereas L. inaequalis and L. bottae are largely sympatric and occur in the Red Sea and Indian Ocean (Fig. 6b).

Distribution: Western and central Pacific Ocean (Papua New Guinea, New Caledonia, Australia). Possibly in Japan

484 although the record in Nishihira and Veron (1995) could not be confirmed because the published image is that of a specimen from Australia already published by Veron et al. (1977: Fig. 301).

Leptastrea magaloni sp. n. Benzoni and Arrigoni, 2020 (Fig. 3, Figs. S1_6, S4y-ab)

Etymology: This species is named after Mme Helene Magalon (Université de La Réunion), chief scientist and organizer of the 2016 MAD Expedition to north Madagascar during which this species previously only collected in Mayotte Island was detected and collected.

Type material: Holotype MNHN-IK-2012-9823 Bouzi, Mayotte Island (1248'44.94"S, 45²14'29.16"E), Tara Oceans Expedition, 18/06/2010 (coll. F. Benzoni: UNIMIB MY345).

Other material examined: Madagascar: MTQ G62190 Nosy Be (13²0'0"S; 48¹5'0"E), Jan 2002 (coll. J.E.N. Veron); MNHN-IK-2016-230 (coll. code IRD MD260) west Nosy Be (13¹9'28.10"S, 48 4'37.82"E), 30/10/2016, MAD Expedition (coll. F. Benzoni); IRD, MAD Expedition (coll. F. Benzoni): MD222 Nosy Lava west (14³3'17.29"S, 47³3'59.71"E), 27/10/2016; MD225 Nosy Lava west (14³3'17.29"S, 47³3'59.71"E), 27/10/2016;

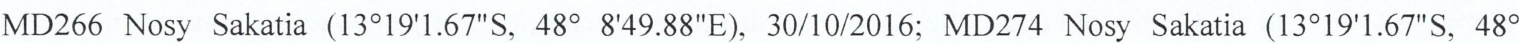
8'49.88"E), 30/10/2016; South Africa: BMNH 1961.7.18.3-5 Inyoni, 1948 (coll. T.A. Stephenson).

Description: Corallum encrusting to massive (Fig. 3a-c, Fig. S1_6), circular to irregular in outline, the largest colony observed $20 \mathrm{~cm}$ in diameter. Budding predominantly extracalicular (Fig. 3b, g), occasionally intracalicular (Fig. 3d). Corallites plocoid, variably exsert but not inclined on the corallum surface (Fig. S1_6a-e). Coenosteum present, 
compact, and variably developed (Fig. 3a-h). Calice outline mainly circular to elliptical (Fig. 3a-d, g), irregular with rounded corners in some specimens (Fig. 3e-f, h-i). Calice average maximum diameter $4.7 \mathrm{~mm}( \pm 0.7$ s.d.) and minimum diameter $3.9 \mathrm{~mm}$ ( \pm 0.6 s.d.) (Data S5). Four complete cycles of radial elements are present (Fig. 3h-i, k), a fifth incomplete one can be observed in larger corallites (Fig. S4y). S1 and S2 equal or sub-equal, septa of higher cycles increasingly thinner and shorter (Fig. 3k). S1 and S2 upper septal margin slightly arched (Fig. 3i, 1). S1-2 reach the columella, S3 and S4 free (Fig. 3g-h) or fused with S2 and S3, respectively (Fig. 3e-f, Fig. S4y, aa-ab). S1-3 bear at their proximal end a granular palar structure of the same size and shape as the columellar processes. The inner upper margin of S3 forms obvious paddle-shaped structures (white arrows in Fig. 3k). S4 devoid palar structures (Fig. 3k). Septal sides densely covered in obvious granules (Fig. 3j-1). Beyond the corallite wall, radial elements form granulated costae which continue over the coenosteum (Fig. 3j). Columella composed of granules (Fig. 3h-i), $1.1 \mathrm{~mm}$ ( \pm 0.1 s.d.) in maximum diameter, and $0.8 \mathrm{~mm}( \pm 0.1 \mathrm{s.d}$.$) in minimum diameter.$

Polyps of Leptastrea magaloni sp. n. are mostly typically fully extended at daytime (Fig. S1_6a-c, f-g), with green or brown tentacles, and a distinctive white oral disc (Fig. S1_6). The tissue among the polyps is beige to brown (Fig. S1_6f, g). This species was encountered between 15 and $25 \mathrm{~m}$ in turbid and protected environments, often growing on hard substrate partially or completely covered in terrigenous sediment.

Molecular phylogeny: Recovered as a monophyletic lineage (clade IV) with high node support values in all phylogenetic trees presented in this study (Figs. 4-5). This species is sister to the lineage leading to L. bottae and $L$. inaequalis (Fig. 6a). The three species thus belong to a lineage which appears to be restricted to the Red Sea and Indian Ocean regions.

Remarks: Among its congeners, Leptastrea magaloni sp. n. is similar to, yet distinct from, L. purpurea and $L$. aequalis. Within the wide range of L. purpurea morphological variability (Fig. S4a-h), L. magaloni sp. n. most closely resembles specimens displaying the L. pruinosa morphology (Figs. 1e-h), a species here synonymised with $L$. purpurea. However, although average calice and columella diameter are similar in L. magaloni sp. n. and L. purpurea, the two species can readily be told apart: the former has distinctly plocoid, typically protruding, more rounded and uniformly sized corallites, while the latter is characterised by cerioid to sub-cerioid, polygonal and variably sized corallites within the same corallum (Fig. S4a-h). Furthermore, L. magaloni sp. n. polyps are usually fully extended at daytime, a condition seldom observed in the field for $L$. purpurea (Fig. S1_1a-e, g). However, when tentacles of $L$. purpurea are fully extended (Fig. S1_1f), they are shorter, thinner, and less crowded than those of L. magaloni sp. n. 
(Fig. S1_6f-g). Leptastrea aequalis, originally described from from Cocos (Keeling) Atoll, shares with L. magaloni sp. n. a similar plocoid to sub-plocoid arrangement, a rounded calice outline, and protruding corallites. Based on the holotype (WAM Z12912) illustrations and the original description (Veron 2002: Figs. 306-307), and the specimens housed at MTQ identified as L. aequalis by JEN Veron, differences with L. magaloni sp. n. are clear. Corallite and columella size are larger in L. magaloni sp. n. (4.0-5.4 mm) than in L. aequalis (2.5-3.5 mm) (Veron 2002). Moreover, in the latter species "there are no paliform lobes" (Veron 2002: 168), while palar structures are variably but consistently developed in the former species. Finally, in L. aequalis corallites are often uniformly inclined on the colony surface, while in L. magaloni sp. n. they can be variably exsert from the coenosteum but not inclined.

Distribution: Southern and western Indian Ocean (SWIO). Currently reported from Mayotte Island, north Madagascar, and South Africa.

\section{Leptastrea purpurea (Dana, 1846)}

(Figs. 1a-h, S1_1, S4a-h)

Astraea (Fissicella) purpurea Dana, 1846.

Leptastrea purpurea (Dana, 1846) Crossland, 1952, Pl. I, Fig. 5, Pl. III, Fig. 3; Chevalier 1975, Pl. II, Fig. 3-4, Pl. III, Fig. 2; Veron et al. 1977, Figs. 303-310, 467; Wijsman Best 1980, Pl. 3, Figs. 1-2; Scheer and Pillai 1983, Pl. 31 , Figs. 11-12; Sheppard and Sheppard 1991, Fig. 159; Veron 2000, Figs. 1, 3-5; Claereboudt 2006 and figures therein; Dai and Horng 2009 and figures therein; Al Tawaha et al. 2019, Figs. 1-4.

Leptastrea pruinosa Crossland, 1952 Crossland, 1952, Pl. III, Fig. 1; Veron et al 1977, Figs. 319-321, 323-324, 326; Wijsman Best 1980, Pl. 2, Fig. 1; Veron 2000, Fig 8; Claereboudt 2006 and figures therein; Dai and Horng 2009 and figures therein; Pichon et al. 2010, Figs. 1, 4.

Leptastrea cf pruinosa Crossland, 1952 Chevalier 1975, Pl. II, Fig. 5, Pl. III, Fig. 7.

Leptastrea transversa Klunzinger, 1879 Chevalier 1975, Pl. II, Fig. 7; Veron et al 1977, Figs. 314-316, 468; Veron 2000, Figs. 4, 6 .

Holotype: USNM 75, Fiji, U.S. Exploring Expedition.

Other material examined: complete list in Data S2.

Remarks: Both genomic and morphological data clearly indicate that the distinction between L. purpurea and $L$. pruinosa is unnecessary and, therefore, the latter species is formally considered a junior synonym of the former taxon. 
From a genomic point of view, the two species are mixed within a single lineage (clade II) in the phylogenetic trees based on both the holobiont and the coral datasets (Fig. 4) and no genomic distinction between them is found. This is a robust result considering that the two datasets include a total of 3,701 and 9,573 loci, respectively. The phylogenomic analyses are further confirmed by the species delimitation analysis BFD* (Table 1), where the best-supported model is the one considering L. purpurea and L. pruinosa as a single species (model 5, MLE $=-12,650.36, \mathrm{BF}=-$ ), in constrast to the scenario where the two species are considered as distinct taxa (model 6, MLE $=-12,659.39, \mathrm{BF}=$ 18.06). From a morphological point of view, there are differences between the holotypes of the two species (Fig. 1) mainly in terms of corallite arrangement (i.e more ceriod in L. purpurea and plocoid in L. pruinosa). However, the study of a large collection of specimens allowed us to verify that these two typical morphologies fall within the range of variation of the same species. Thus, concordant genomic and morphologic evidence support the synonymy.

\section{Identification key to the species examined in this study}

1a Adjacent corallite walls not fused and distinct 2

1b Adjacent corallite walls fused or touching 4

2a Calice outline mostly circular 3

2b Calice outline polygonal or irregular 4

3a Grooves among adjacent corallites present 5

$\begin{array}{ll}\text { 3b Grooves among adjacent corallites absent } & 6\end{array}$

4a Columella lamellar or composed of 2-4 aligned granules L. transversa

4b Columella circular to elliptical and composed of $>4$ granules L. purpurea

5a Three complete cycles of septa $\quad$ L. inaequalis

5b Two complete cycles of septa (third incomplete or absent) L. gibbosa sp. n.

6a Three complete cycles of septa L. bottae

6b Four complete cycles of septa $\quad$ L. magaloni sp. n.

\section{Discussion}

In this study we evaluated species boundaries within a scleractinian coral genus sampled across the Indo-Pacific by integrating genomics, morphology, and biogeography. The combination of methods allowed us to delimit six 
600

601

602

603

604

605

606

607

608

609

610

species in Leptastrea, two of which new to science, and to update their geographic distribution. All species were fully resolved in the phylogenomic framework based on ezRAD data and could be distinguished based on revised diagnostic morphological characters as shown in the proposed identification key. The novel aspects of this study are: the widespread sampling spanning the entire Indo-Pacific, the unprecedented phylogenetic resolution obtained from the ezRAD method, and the integration of different lines of evidence for species delimitation and ultimately in a taxonomic revision.

We are now able to answer the three questions raised in the introduction: (a) closely related and morphologically similar coral species can be distinguished by analyzing large collection of specimens spanning nearly complete geographic ranges of species under the integration of reduced-genome data (and not a set of barcoding genes) with detailed morphometric analyses; (b) once a robust species delimitation framework is obtained (a), we can look at diagnostic morphological characters among the large collection of specimens, unambiguously telling apart intraspecific and interspecific morphological variation, as we presented with the identification key; (c) once diagnostic skeletal structures are found for species (b), we can better understand the species distribution ranges by correctly identifying specimens deposited at museum collections and/or illustrated in reference literature.

\section{Improving phylogeny and species delimitation resolution in corals}

Our phylogenetic and species delimitation analyses based on ezRAD data provided a robust and fully resolved hypothesis of the examined Leptastrea across the tropical Indo-Pacific. The results from all genomic analyses consistently resolved six species, partially rejecting the current taxonomy of seven species ascribed to the genus (Figs. 4 and 6, Table 1). The phylogenetic resolution we obtained from both the holobiont and coral ezRAD datasets is unprecedented. Such resolution is even more remarkable when compared to the results obtained from the two traditional barcoding loci COI and ITS (Fig. S3) and from the nearly complete mitogenomes and rDNA arrays (Fig. 5). In fact, COI and ITS supported the separation of only two out of the six species, i.e. L. gibbosa sp n. and $L$. purpurea, whereas $L$. magaloni sp. n., L. bottae, and $L$. inaequalis were consistently grouped in an unresolved polytomy. Considering the nearly complete mitogenome and rDNA sequences improved the overall tree resolution. However, the trees obtained from these datasets still persistently failed to separate $L$. bottae from $L$. inaequalis, two admittedly morphologically similar but distinct species (Fig. 1, Fig. S4q-x). The comparison among these different genetic datasets in Leptastrea may lead to a re-evaluation of the published molecular phylogenies and species 
614 delimitation attempts in corals based on single or few barcoding genes (Kitahara et al 2016). Although the mitochondrial genome of Anthozoa and Porifera evolves slower than the one of the other Metazoa (Shearer et al.

616 2002; Hellberg 2006), several mitochondrial regions have been frequently used to infer phylogenetic relationships among corals (Kitahara et al. 2016). Based on our results, although the application of single barcodes represents a useful strategy for rapid coral species assessments, the results obtained from mitochondrial and rDNA regions should be cautioned for species level resolution because of their low substitution rates.

In our study, the phylogenetic analyses inferred with more loci, and thus more missing data, were better resolved at both deep and shallow nodes than the ones based on less loci and low percentage of missing data (Fig. 4, Fig. S2). Notably, the phylogeny reconstructions obtained with about 2,000 loci from both coral and holobiont datasets without any missing data failed to distinguish L. bottae and L. inaequalis. Nevertheless, although the presence of six species was consistently detected with very strong support values, we observed notable differences in gene tree topologies between the concatenation-based "holobiont-max" and "coral-max" phylogenies, in particular the position of $L$. gibbosa sp. n. (Fig. 4). Moreover, the fully-supported topology of the species tree inferred from unlinked biallelic coral SNPs without missing data (Fig. 6a) was identical to the one of the gene tree based on the "holobiont-max" dataset (Fig. 3a). Differences in topologies inferred from RADseq data have been already documented in several cases (Hou et al. 2015; Massatti et al. 2016; Suchan et al. 2017; Rancilhac et al. 2019). In our case, several factors may be hypothesized to explain this discordance: (a) the holobiont tree is poorly supported at several nodes and especially the phylogenetic position of L. gibbosa sp. n. is not resolved under the ML criterion; (b) difficulties in resolving interspecific relationships may be associated with incongruences in the phylogenetic signals associated with different sets of loci from the holobiont and coral supermatrices (Gori et al. 2016); (c) the different filtering options yielding to various levels of missing data may have generated different tree topologies (Wagner et al. 2013; Eaton and Ree 2013); (d) concatenating sequence data from thousands of loci does not account for the individual history of these loci (Sanderson et al. 2003), and, since gene histories differ from species histories, concatenation approaches in some cases do not produce accurate species trees (Kubatko and Degnan 2007); (e) the proportion of missing data increases with interspecific evolutionary distances as a consequence of the loss of the restriction sites (Gautier et al. 2013; Cariou et al. 2013); (f) in case of rapid and recent radiations, gene trees may depict different evolutionary histories due to incomplete lineage sorting (Avise et al. 2008) and RADseq datset may be useful for resolving species boundaries but more research is needed to develop best practices for defining interspecific relationships. Unfortunately, in our case 
we cannot provide any age estimates of the analyzed species due to lack of fossil calibration. Indeed, we retrieved images of the few occurrences supposed to belong to extinct Leptastrea species (Paleobiology Database, https://paleobiodb.org/) but the morphology of these specimens could not be unequivocally associated to this genus.

Incongruence between traditional morphology- and molecular-based species identification is common in scleractinian corals and corals more broadly (Kitahara et al. 2016; McFadden et al. 2017). Although cryptic species have been documented in several coral genera (Flot et al. 2011; Stefani et al. 2011; Pinzón et al. 2013; Warner et al. 2015; Richards et al. 2016; Arrigoni et al. 2019), the discordance between morphology and genetics based on barcoding genes is frequently caused by methodological problems associated with both datasets. It is often challenging to separate intraspecific and interspecific morphological variation, and several skeletal structures are affected by convergence, stasis, and homoplasy (Fukami et al. 2008; Paz-García et al. 2015). This has caused uncertainties and led to the description of morphospecies not representing the actual outcome of an evolutionary process. Additional identification problems and incorrect synonymies have stemmed from a lack of consideration for the actual type material morphology. In fact, coral morphospecies thought to be widespread in the Indo-Pacific have recently been shown to be comprised of multiple, often geographically distinct, lineages (Forsman et al. 2009; Schmidt-Roach et al 2014). This is the case of L. bottae and L. inaequalis, historically confused (Veron 2000) or synonymised (Chevalier 1975; Veron et al. 1977; Wijsman-Best 1980; Scheer and Pillai 1983; Sheppard and Sheppard 1991) (Data S2) and considered widespread (Veron 2000) due to identification evidently not based on type material examination. Our results showed that the two species are actually distinct and restricted to the Red Sea and Indian Ocean where they are sympatric (Al Tawaha et al. 2019; Berumen et al. 2019), while their records from the Pacific (Crossland 1952; Chevalier 1975; Veron et al. 1977; Veron 2000) were based on material here formally described as L. gibbosa sp. n., a genetically (Figs. 4-6a) and morphologically (Fig 7, Data S5) distinct species. In other cases, such as in that of $L$. purpurea and L. pruinosa, two or more nominal species were shown to be different names used to refer to a single morphologically variable species (Forsman et al. 2010; Carlon et al. 2011; Paz-García et al. 2015; Arrigoni et al. 2016b). Nevertheless, unresolved molecular phylogenies or species complexes may also derive from insufficient genetic variation and lack of phylogenetic resolution of barcoding genes (Frade et al. 2010; Prada et al. 2014; Arrigoni et al. 2016a; Terraneo et al. 2016). The advent of reduced-genome techniques such as RADseq significantly overcome the limitations ofwork based on barcoding loci (Andrews et al. 2016). For example, RADseq approach fully-resolved species boundaries within the common scleractinian Pocillopora (Johnston et al. 2017), and the speciose octocorals 
Chrysogorgia (Pante et al. 2015), Paragorgia (Herrera and Shank 2016), and Sinularia (Quattrini et al. 2019). For all these taxa, traditional molecular markers have proved uninformative and previously generated unresolved phylogenies. Therefore, RADseq may opened a new era for coral systematics and phylogeny. This approach produces robust species delimitation hypotheses that may be confronted with the outcome from other lines of evidence such as morphology and biogeography with the final objective of a solid taxonomic framework for scleractinian corals.

\section{Leptastrea taxonomy}

The bewildering geographical morphological variation of Leptastrea, and of $L$. purpurea in particular, is welldocumented in the literature (Matthai 1914; Chevalier 1975; Veron et al. 1977; Wijsman-Best 1980; Scheer and Pillai 1983 ) and has led several authors to confuse this species with other congeners, and especially with the equally common and widespread L. transversa. For example, Wijsman-Best (1980), referring to L. purpurea, L. transversa, and $L$. bottae, stated "in these the geographical variation extends beyond the interpopulational variation and therefore they may be regarded as dynamically evolving species". Indeed, our morphometric analyses confirmed the skeleton variability of the examined species, and of L. purpurea in particular. However, the present study demonstrated that this statement is incorrect because the three species are actually clearly genetically and morphologically distinct, with L. bottae also being distinct from the valid L. inaequalis, as already discussed in the previous paragraph.

Based on our measurements, L. purpurea could not be distinguished from material matching the L. pruinosa type morphology and L. magaloni sp. n. (Figs. 1 and 7, Data S5). However, while our genomic results showed that the typical L. purpurea and L. pruinosa morphotypes belong to the same species, and thus led us to consider the latter a junior synonym of the former (Data S2), they also provided evidence that L. magaloni sp. n. belongs to a separate lineage from L. purpurea. Indeed, although the variables we measured did not allow us to separate L. purpurea from L. magaloni sp. n. specimens, the latter has a distinctively plocoid corallite arrangement, a more regular septal plan and, overall, a smaller variability of corallite and columella dimensions (Data S5). Moreover, differences in polyp morphology in vivo were illustrated for the two species (Fig. S1_1 and S1_6) and highlighted. Specimens of $L$. transversa, including the species holotype (Fig. 1i), albeit similar in corallite shape and arrangement to the L. purpurea ones with smaller calice dimensions, were readily distinguished based on the typically thinner columella composed of a series of aligned granules, often fused to form a dash shaped structure (Figs. 1j-1) with which S1 and S2 fuse. Hence, despite considerable confusion between the two species in the published literature (Data S1), they are actually readily 
distinct upon visual examination of the columella. Phylogenetic and species delimitation analyses based on genomic data confirmed the morphometric findings showing that the former two species were reciprocally monophyletic even with the inclusion of samples collected from very distant or remote localities, such as the Red Sea and French Polynesia.

Leptastrea gibbosa sp. n., identified as L. bottae or L. cf bottae so far (Veron et al. 1977; Veron 2000), is, among the examined species, the species with the smallest corallite features and, despite similarities with $L$. bottae and $L$. inaequalis in corallite shape and arrangement, is readily distinct from both species. The biogeographic implications of this finding are discussed in the next section.

Two Leptastrea nominal species currently considered valid were not included in our analyses, namely L. aequalis and L. bewickensis. Nevertheless, we examined the species holotypes and specimens housed at the MTQ and both species appear to be at least morphologically distinct and are here considered valid. Differences between the distinct L. aequalis and L. magaloni sp. n. are discussed in detail in the Taxonomic Account. Leptastrea bewickensis remains a more enigmatic species and its relationships with the morphologically similar L. purpurea and the rest of the species in the genus need to be ascertained. Finally, based on the morphological examination of specimens of Cyphastrea agassizi (Vaughan, 1907) housed at the MTQ, the current species assignation is doubtful and further studies on freshly collected material are needed to verify if the species original assignation to the genus Leptastrea was, in fact, correct. Finally, it is important to mention that another benefit of ezRAD is that many markers like SNPs and nearly complete mitogenomes should be compatible and comparable among studies. Therfore, it will be easy to phylogenetically include and compare L. bewickensis and C. agassizi within our genomic and genetic analyses.

\section{Leptastrea biogeography}

It is well-known and documented that the coral maximum biodiversity is located in an area of the Indo-Malay Archipelago known as the Coral Triangle (Hoeksema 2007). The high number of species living in the Coral Triangle seems to be largely due to range expansion into this area of taxa that have evolved elsewhere, thus the region is considered as a center of accumulation of marine biodiversity (Huang et al. 2018). A growing number of studies aimed to evaluate scleractinian species boundaries found unexpected biogeographic patterns and several lineages restricted to the Indian Ocean (for a review see Kitahara et al. 2016). Genetic data revealed several cases of evolutionary breaks between Indian and Pacific coral populations traditionally identified as the same widespread Indo-Pacific species, and 
that these de facto are included multiple distinct species with allopatric and geographically circumscribed distributions (Flot et al. 2011; Stefani et al. 2011; Arrigoni et al. 2012; Pinzón et al. 2013; Kitano et al. 2014; Huang et al. 2014; Richards et al. 2016; Gélin et al. 2017, 2018; Arrigoni et al. 2018). During the last decade, combined morphomolecular approaches described new genera and species endemic to the northern and/or western Indian Ocean, thus increasing the coral biodiversity of this area (Benzoni and Stefani 2012; Benzoni et al. 2012; Terraneo et al. 2014; Arrigoni et al. 2015, 2016b, 2016c). Therefore, it is becoming increasingly clear that, although species richness is highest in the Coral Triangle, the Indian Ocean displays a higher number of endemisms possibly as the result of a combination of higher speciation rates and lower extinction rates in its peripheral areas such as the Red Sea and the western Indian Ocean (Huang et al. 2018; McFadden et al. 2019).

The integrated approach we adopted to define species boundaries within Leptastrea corroborated the above mentioned findings and provided a new perspective on the biogeography of the genus. So far, all the analyzed species have been considered to be widely distributed throughout the Indo-Pacific, from the Red Sea to the Central Pacific (distribution maps in Veron 2000). Our results showed, however, that only L. purpurea and L. transversa display such a widespread geographic distribution without intraspecific genomic breaks. Conversely, L. gibbosa sp. n. only occurs in the Western and central Pacific Ocean, L. magaloni sp. n. seems to be an endemism of the Mozambique Channel (although the species actual distribution could extend further in the SWIO), whereas L. bottae and L. inaequalis occur in the Red Sea and Arabian Sea, and then extend in various localities of the Indian Ocean. Therefore, Leptastrea actually displays its peak of diversity and endemism in the western and northern Indian Ocean (Fig. 6b). These results confirm the evolutionary distinctiveness of corals occurring in the northern and western Indian Ocean (Obura 2012, 2016). Interestingly, distributional data of extant coral species seem to indicate the presence of two distinct centers of diversity in this basin which are the northern Mozambique Channel and the Red Sea (Obura 2012; Veron et al. 2015). Fossils and phylogenetic data suggest the presence of multiple centers of origin in this area and, in particular, a first one in the Paleogene Tethys Sea and a second one in the Neogene Red Sea and Arabian Sea (Obura 2016; Arrigoni et al. 2019). Important tectonic changes occurred in what is now the Indian Ocean during both the Paleogene and the Neogene and may have promoted isolation and speciation events (Schettino and Turco 2011; Keith et al. 2013; Obura 2016). Unfortunately, in the absence of a reliable fossil record for Leptastrea or estimates of its lineage ages, we cannot currently test whether the three species of Leptastrea restricted to the Indian Ocean originated in the Paleogene or Neogene. 
756 Acknwledgements This project was supported by funding from KAUST (award \# FCC/1/1973-21 and baseline research funds to MLB). This research was undertaken in accordance with the policies and procedures of KAUST. Permissions relevant for KAUST to undertake the research have been obtained from the applicable governmental agencies in the Kingdom of Saudi Arabia. We wish to thank A Gusti (KAUST), the captain and crew of the MV Dream-Master, and the KAUST Coastal and Marine Resources Core Lab for fieldwork logistics in the Red Sea. In Yemen, fieldwork organization, logistics and sampling permits from the relevant authorities were possible hanks to the collaboration of E Dutrieux (Creocean), CH Chaineau (Total SA), R Hirst, and M Abdul Aziz (YLNG). We are grateful to E Karsenti (EMBL) and E Bougois (Tara Expeditions), the OCEANS Consortium for allowing sampling during the Tara Oceans expedition in Djibouti and Mayotte. We thank the commitment of the following people and additional sponsors who made this singular expedition possible: CNRS, EMBL, Genoscope/CEA, VIB, Stazione Zoologica Anton Dohrn, UNIMIB, ANR (projects POSEIDON/ANR-09-BLAN-0348, BIOMARKS/ANR-08BDVA-003, PROMETHEUS/ANR-09-GENM-031, and TARA-GIRUS/ANR-09-PCS-GENM-218), EU FP7 (MicroB3/No.287589), FWO, BIO5, Biosphere 2, agnès b., the Veolia Environment Foundation, Region Bretagne, World Courier, Illumina, Cap L'Orient, the EDF Foundation EDF Diversiterre, FRB, the Prince Albert II de Monaco Foundation, Etienne Bourgois, the Tara schooner, and its captain and crew. Tara Oceans would not exist without continuous support from 23 institutes (http://oceans.taraexpeditions.org). This article is contribution number $\underline{\mathbf{X X}}$ of the Tara Oceans Expedition 2009-2012. New Caledonia data and specimens were obtained during the IRD CORALCAL1 (http://dx.doi.org/10.17600/7100020), CORALCAL2 ( CORALCAL3 (http://dx.doi.org/10.17600/9100010), CORALCAL4 (http://dx.doi.org/10.17600/12100060), BIBELOT (http://dx.doi.org/10.17600/14003700), and CORALCAL5 (http://dx.doi.org/10.17600/15004300) expeditions on the RV Alis. We are grateful to the chief scientists and cruise organisers C Payri (IRD), C Fauvelot (IRD) for invitation and financial support to join and valuable help with sampling authorisations. Material from Madagascar was collected during the MAD (http://dx.doi.org/10.17600/16004700) expedition on the RV Antea organised by $\mathrm{H}$ Magalon (ULR). The MADANG expedition specimens were obtained during the "Our Planet Reviewed" Papua Niugini expedition (http://dx.doi.org/10.17600/12100070) organised by Muséum National d'Histoire Naturelle (MNHN), Pro Natura International (PNI), Institut de Recherche pour le Développement (IRD), 

organizers acknowledge funding from the Total Foundation, Prince Albert II of Monaco Foundation, Fondation EDF, Stavros Niarchos Foundation, and Entrepose Contracting, and in-kind support from the Divine Word University (DWU). Material from Kavieng, PNG, was sampled during the KAVIENG Expedition (https://doi.org/10.17600/14004400). The expedition operated under a permit delivered by the Papua New Guinea Department of Environment and Conservation. Material from the Coral Sea, Australia, was sampled in under Permit No. AU-COM2018-437. The authors wish to thank A.H. Baird (JCU), M. Pratchett (JCU), and Hugo Harrison (JCU) and the relevant staff at Parks Australia. We are grateful to A. Andouche (MNHN), M. Castellin (MNHN), P. Lozouet not in any circumstance be regarded as stating an official position of the European Commission. We are grateful to Z.H. Forsman (UH Manoa) and one anonymous reviewer for their useful corrections and suggestions.

\section{Compliance with ethical standards}

Conflict of interest On behalf of all authors, the corresponding author states that there is no conflict of intest.

\section{References}

Al Tawaha M, Benzoni F, Eid E, Abu Awali A (2019) The hard corals of Jordan, a field guide. Amman, Jordan, the Royal Marine Conservation Society of Jordan

802

Andrews KR, Good JM, Miller MR, Luikart G, Hohenlohe PA (2016) Harnessing the power of RADseq for ecological and evolutionary genomics. Nat Rev Genet 17:81-92

Arrigoni R, Stefani F, Pichon M, Galli P, Benzoni F (2012) Molecular phylogeny of the robust clade (Faviidae, Mussidae, Merulinidae, and Pectiniidae): an Indian Ocean perspective. Mol Phylogenet Evol 65:183-193

Arrigoni R, Berumen ML, Terraneo TI, Caragnano A, Bouwmeester J, Benzoni F (2015) Forgotten in the taxonomic literature: resurrection of the scleractinian coral genus Sclerophyllia (Scleractinia, Lobophylliidae) from the Arabian Peninsula and its phylogenetic relationships. Syst Biodivers 13:140-163

Arrigoni R, Benzoni F, Terraneo TI, Caragnano A, Berumen ML (2016a) Recent origin and semi-permeable species boundaries in the scleractinian coral genus Stylophora from the Red Sea. Sci Rep 6:34612

Arrigoni R, Berumen ML, Chen CA, Terraneo TI, Baird AH, Payri C, Benzoni F (2016b) Species delimitation in the reef coral genera Echinophyllia and Oxypora (Scleractinia, Lobophylliidae) with a description of two new species. Mol Phylogenet Evol 105:146-159

Arrigoni R, Benzoni F, Huang D, Fukami H, Chen CA, Berumen ML, Hoogenboom M, Thomson DP, Hoeksema BW, Budd AF, Zayasu Y, Terraneo TI, Kitano YF, Benzoni F (2016c) When forms meet genes: revision of the scleractinian genera Micromussa and Homophyllia (Lobophylliidae) with a description of two new species and one new genus. Contrib Zool 85:387-422

Arrigoni R, Maggioni D, Montano S, Hoeksema BW, Seveso D, Shlesinger T, Terraneo TI, Tietbohl MD, Berumen ML (2018) An integrated morpho-molecular approach to delineate species boundaries of Millepora from the Red Sea. Coral Reefs 37:967-984 
Arrigoni R, Berumen ML, Stolarski J, Terraneo TI, Benzoni F (2019) Uncovering hidden coral diversity: a new cryptic lobophylliid scleractinian from the Indian Ocean. Cladistics 35:301-328

Avise JC, Robinson TJ, Kubatko L (2008) Hemiplasy: a new term in the lexicon of phylogenetics. Syst Biol 57:503507

Baird NA, Etter PD, Atwood TS, Currey MC, Shiver AL, Lewis ZA, Selker EU, Cresko WA, Johnson EA (2008) Rapid SNP discovery and genetic mapping using sequenced RAD markers. PloS ONE 3:e3376

Benzoni F, Stefani F (2012) Porites fontanesii, a new species of hard coral (Scleractinia, Poritidae) from the southern Red Sea, the Gulf of Tadjoura, and the Gulf of Aden. Zootaxa 3447:56-68

Benzoni F, Arrigoni R, Stefani F, Stolarski J (2012) Systematics of the coral genus Craterastrea (Cnidaria, Anthozoa, Scleractinia) and description of a new family through combined morphological and molecular analyses. Syst Biodivers 10:417-433

Berumen ML, Arrigoni R, Bouwmeester J, Terraneo TI, Benzoni F (2019) Corals of the Red Sea. In: Voolstra CR, Berumen ML (eds) Coral Reefs of the Red Sea. Springer Cham, Berlin, pp 123-155

Boero F (2001) Light after dark: the partnership for enhancing expertise in taxonomy. Trends Ecol. Evol. 16:266

Bolger AM, Lohse M, Usadel B (2014) Trimmomatic: a flexible trimmer for Illumina sequence data. Bioinformatics 30:2114-2120

Bouckaert RR (2010) DensiTree: making sense of sets of phylogenetic trees. Bioinformatics 26:1372-1373

Bouckaert R, Heled J, Kühnert D, Vaughan T, Wu CH, Xie D, Suchards MA, Rambaut A, Drummond AJ (2014) BEAST 2: a software platform for Bayesian evolutionary analysis. PLoS Comput Biol 10:e1003537

Bryant D, Bouckaert R, Felsenstein J, Rosenberg NA, Roy-Choudhury A (2012) Inferring species trees directly from biallelic genetic markers: bypassing gene trees in a full coalescent analysis. Mol Biol Evol 29:1917-1932

Budd AF, Fukami H, Smith ND, Knowlton N (2012) Taxonomic classification of the reef coral family Mussidae (Cnidaria: Anthozoa: Scleractinia). Zool J Linnean Soc 166:465-529

Cariou M, Duret L, Charlat S (2013) Is RAD-seq suitable for phylogenetic inference? An in silico assessment and optimization. Ecol Evol 3:846-852

Carlon DB, Budd AF (2002) Incipient speciation across a depth gradient in a scleractinian coral? Evolution 56:22272242

Carlon DB, Budd AF, Lippé C, Andrew RL (2011) The quantitative genetics of incipient speciation: heritability and genetic correlations of skeletal traits in populations of diverging Favia fragum ecomorphs. Evolution 65:34283447

Chevalier JP (1975) Les scléractiniaires de la mélanésie francaise (Nouvelle- Calédonie, lies Chesterfield, lies Loyauté, Nouvelles-Hébrides). Expédition Francaise Sur les Récifs Coralliens de la Nouvelle-Calédonie, Deuxieme Partie. Fond Singer-Polignac, Paris

Crossland C (1952) Madreporaria, Hydrocorallinae, Heliopora and Tubipora. Sci. Rep. Great Barrier Reef Exped. 1928-29. Bull Br Mus Nat Hist Zool 6:85-257

Danecek P, Auton A, Abecasis G, Albers CA, Banks E, DePristo MA, Handsaker RE, Lunter G, Marth GT, Sherry ST, McVean G, Durbin R, 1000 Genome Project Data Processing Subgroup (2011) The variant call format and VCFtools. Bioinformatics 27:2156-2158

Davey JW, Blaxter ML (2010) RADSeq: next-generation population genetics. Brief Funct Genomics 9:416-423

Dimond JL, Gamblewood SK, Roberts SB (2017) Genetic and epigenetic insight into morphospecies in a reef coral. Mol Ecol 26:5031-5042

Drummond AJ, Bouckaert RR (2015) Bayesian evolutionary analysis with BEAST. Harvard University Press, Cambridge

Eaton DAR, Ree RH (2013) Inferring phylogeny and introgression using RADseq data: an example from flowering plants (Pedicularis: Orobanchaceae). Syst Biol 62:689-706

Eaton DA, Spriggs EL, Park B, Donoghue MJ (2017) Misconceptions on missing data in RAD-seq phylogenetics with a deep-scale example from flowering plants. Syst Biol 66:399-412

Flot JF, Blanchot J, Charpy L, Cruaud C, Licuanan WY, Nakano Y, Payri C, Tillier S (2011) Incongruence between morphotypes and genetically delimited species in the coral genus Stylophora: phenotypic plasticity, morphological convergence, morphological stasis or interspecific hybridization? BMC Ecol 11:22

Forsman ZH, Barshis DJ, Hunter CL, Toonen RJ (2009) Shape-shifting corals: molecular markers show morphology is evolutionarily plastic in Porites. BMC Evol Biol 9:45

Forsman ZH, Concepcion GT, Haverkort RD, Shaw RW, Maragos JE, Toonen RJ (2010) Ecomorph or endangered coral? DNA and microstructure reveal Hawaiian species complexes: Montipora dilatatalflabellata/turgescens \& M. patula/verrilli. PLoS ONE 5:e15021 
Forsman ZH, Knapp ISS, Tisthammer K, Eaton DAR, Belcaid M, Toonen RJ (2017) Coral hybridization or phenotypic variation? Genomic data reveal gene flow between Porites lobata and P. compressa. Mol Phylogenet Evol 111:132-148

Frade PR, Reyes-Nivia MC, Faria J, Kaandorp JA, Luttikhuizen PC, Bak RPM (2010) Semi-permeable species boundaries in the coral genus Madracis: introgression in a brooding coral system. Mol Phylogenet Evol 57:10721090

Fukami H, Chen CA, Budd AF, Collins A, Wallace C, Chuang YY, Chen C, Dai CF, Iwao K, Sheppard C, Knowlton N (2008) Mitochondrial and nuclear genes suggest that stony corals are monophyletic but most families of stony corals are not (Order Scleractinia, Class Anthozoa, Phylum Cnidaria). PloS ONE 3:e3222

García-Roselló E, Guisande C, Manjarrés-Hernández A, González-Dacosta J, Heine J, Pelayo-Villami P, GonzálezVilas L, Vari RP, Vaamonde A, Granado-Lorencio C, Lobo JM (2015) Can we derive macroecological patterns from primary Global Biodiversity Information Facility data? Global Ecol Biogeog 24:335-347

Garrison E, Marth G (2012) Haplotype-based variant detection from short-read sequencing. arXiv Prepr arXiv12073907:1-9

Gautier M, Gharbi K, Cezard T, Foucaud J, Kerdelhué C, Pudlo P, Cornuet JM, Estoup A (2013) The effect of RAD allele dropout on the estimation of genetic variation within and between populations. Mol Ecol 22:3165-3178

Gélin P, Postaire B, Fauvelot C, Magalon H (2017) Reevaluating species number, distribution and endemism of the coral genus Pocillopora Lamarck, 1816 using species delimitation methods and microsatellites. Mol Phylogenet Evol 109:430-446

Gélin P, Fauvelot C, Bigot L, Baly J, Magalon H (2018) From population connectivity to the art of striping Russian dolls: the lessons from Pocillopora corals. Ecol Evol 8:1411-1426

Gori K, Suchan T, Alvarez N, Goldman N, Dessimoz C (2016) Clustering genes of common evolutionary history. Mol Biol Evol 33:1590-1605

Hellberg ME (2006) No variation and low synonymous substitution rates in coral mtDNA despite high nuclear variation. BMC Evol Biol 6:24

Herrera S, Shank TM (2016) RAD sequencing enables unprecedented phylogenetic resolution and objective species delimitation in recalcitrant divergent taxa. Mol Phylogenet Evol 100:70-79

Hoeksema BW (2007) Delineation of the Indo-Malayan centre of maximum marine biodiversity: the coral triangle. In: Renema W (ed) Biogeography, time and place: distributions, barriers and islands. Springer Cham, Berlin, pp $117-178$

Hoeksema BW, Cairns S (2019) World List of Scleractinia. Leptastrea Milne Edwards \& Haime, 1849. Accessed through: World Register of Marine Species at: http://www. marinespecies.org/aphia.php?p=taxdetails\&id=204278 on 2019-12-04

Hou Y, Nowak MD, Mirré V, Bjorå CS, Brochmann C, Popp M (2015) Thousands of RAD-seq loci fully resolve the phylogeny of the highly disjunct arctic-alpine genus Diapensia (Diapensiaceae). PLoS One 10: e140175

Huang D, Benzoni F, Fukami H, Knowlton N, Smith ND, Budd AF (2014) Taxonomic classification of the reef coral families Merulinidae, Montastraeidae, and Diploastraeidae (Cnidaria: Anthozoa: Scleractinia). Zool J Linnean Soc 171:277-355

Huang D, Benzoni F, Arrigoni R, Baird AH, Berumen ML, Bouwmeester J, Chou LM, Fukami H, Licuanan WY, Lovell ER, Mieri R, Todd PA, Budd AF, Meier R (2014) Towards a phylogenetic classification of reef corals: the Indo-Pacific genera Merulina, Goniastrea and Scapophyllia (Scleractinia, Merulinidae). Zool Scripta 43:531-548

Huang D, Goldberg EE, Chou LM, Roy K (2018) The origin and evolution of coral species richness in a marine biodiversity hotspot. Evolution 72:288-302

Hughes TP. Barnes ML, Bellwood DR, Cinner JE, Cumming GS, Jackson JB, Kleypas J, van de Leemput IA, Lough JM, Morrison TH. Palumbi SR, van Nes EH. Scheffer M (2017) Coral reefs in the Anthropocene. Nature 546:8290

Hughes TP, Anderson KD, Connolly SR, Heron SF, Kerry JT, Lough JM., Baird AH, Baum JK, Berumen ML, Bridge TC, Claar DC, Eakin CM, Gilmour JP, Graham NAJ, Harrison H, Hobbs JPA, Hoey AS, Hoogenboom M, Lowe RJ, McCulloch MT. Pandolfi JM, Pratchett M, Schoepf V, Torda G, Wilson SK (2018) Spatial and temporal patterns of mass bleaching of corals in the Anthropocene. Science 359:80-83

Hughes TP, Kerry JT, Baird AH, Connolly SR, Chase TJ, Dietzel A, Hill T, Hoey AS. Hoogenboom MO. Jacobson M, Kerswell A, Madin JS, Mieog A, Paley AS, Pratchett MS, Torda G, Woods RM (2019) Global warming impairs stock-recruitment dynamics of corals. Nature 568:387-390

Johnson CN, Balmford A, Brook BW, Buettel JC, Galetti M, Guangchun L, Wilmshurst JM (2017) Biodiversity losses and conservation responses in the Anthropocene. Science 356:270-275 
Johnston EC, Forsman ZH, Flot JF, Schmidt-Roach S, Pinzón JH, Knapp IS, Toonen RJ (2017) A genomic glance through the fog of plasticity and diversification in Pocillopora. Sci Rep 7:5991.

Kass RE, Raftery AE (1995) Bayes factors. J Am Stat Assoc 90:773-795

Katoh K, Standley DM (2013) MAFFT multiple sequence alignment software version 7: improvements in performance and usability. Mol Biol Evol 30:772-780

Keith SA, Baird AH, Hughes TP, Madin JS, Connolly SR (2013) Faunal breaks and species composition of IndoPacific corals: the role of plate tectonics, environment and habitat distribution. Proc R Soc Lond 280:20130818

Klunzinger CB (1879) Die Korallenthiere des Rothen Meeres, 3. Gutmann, Berlin

Kitahara MV, Fukami H, Benzoni F, Huang D (2016) The new systematics of Scleractinia: integrating molecular and morphological evidence. In: Dubinsky Z, Goffredo S (eds) The Cnidaria, past, present and future. Springer Cham, Berlin, pp 41-59

Kitano YF, Benzoni F, Arrigoni R, Shirayama Y, Wallace CC, Fukami H (2014) A phylogeny of the family Poritidae (Cnidaria, Scleractinia) based on molecular and morphological analyses. PLoS ONE 9:e98406

Kitchen SA, Crowder CM, Poole AZ, Weis VM, Meyer E (2015) De novo assembly and characterization of four anthozoan (phylum Cnidaria) transcriptomes. G3: Genes Genom Genet 5:2441-2452

Knapp IS, Puritz JB, Bird CE, Whitney JL, Sudek M, Forsman ZH, Toonen RJ (2016) ezRAD-an accessible nextgeneration RAD sequencing protocol suitable for non-model organisms v3. 1. Protocols io Life Sciences Protocol Repository. http://dx.doi.org/10.17504/protocols.io.e9pbh5n

Knowlton N (2001) The future of coral reefs. Proc Nat Acad Sci USA 98:5419-5425

Kubatko LS, Degnan JH (2007) Inconsistency of phylogenetic estimates from concatenated data under coalescence. Syst Biol 56:17-24

Lanfear R, Frandsen PB, Wright AM, Senfeld T, Calcott B (2016) PartitionFinder 2: new methods for selecting partitioned models of evolution for molecular and morphological phylogenetic analyses. Mol Biol Evol 34:772773

Langmead B, Salzberg SL (2012) Fast gapped-read alignment with Bowtie 2. Nature Methods 9:357

Leaché AD, Fujita MK, Minin VN, Bouckaert RR (2014) Species delimitation using genome-wide SNP data. Syst Biol 63:534-542

Li H, Durbin R (2009) Fast and accurate short read alignment with Burrows-Wheeler transform. Bioinformatics 25:1754-1760

Li H, Handsaker B, Wysoker A, Fennell T, Ruan J, Homer N, Marth G, Abecasis G, Durbin R, 1000 Genome Project Data Processing Subgroup (2009) The Sequence Alignment/Map format and SAMtools. Bioinformatics 25:20782079

Lischer HE, Excoffier L (2011) PGDSpider: an automated data conversion tool for connecting population genetics and genomics programs. Bioinformatics 28:298-299

Massatti R, Reznicek AA, Knowles LL (2016) Utilizing RADseq data for phylogenetic analysis of challenging taxonomic groups: a case study in Carex sect. Racemosae. Am J Bot 103:337-347

Matthai G (1914) No. I. -A revision of the recent colonial Astræidæ possessing distinct corallites. Trans Linn Soc Lond 17:1-140

McCauley DJ, Pinsky ML, Palumbi SR, Estes JA, Joyce FH, Warner RR (2015) Marine defaunation: animal loss in the global ocean. Science 347:1255641

McFadden CS, Haverkort-Yeh R, Reynolds AM, Halàsz A, Quattrini AM, Forsman ZH, Benayahu Y, Toonen RJ (2017) Species boundaries in the absence of morphological, ecological or geographical differentiation in the Red Sea octocoral genus Ovabunda (Alcyonacea: Xeniidae). Mol Phylogenet Evol 112:174-184

McFadden CS, Gonzalez A, Imada R, Shi SS, Hong P, Ekins M, Benayahu Y (2019) Molecular operational taxonomic units reveal restricted geographic ranges and regional endemism in the Indo-Pacific octocoral family Xeniidae. J Biogeogr 46:992-1006

Metzker ML (2010) Sequencing technologies-the next generation. Nat Rev Genet 11:31-46

Miller MA, Pfeiffer W, Schwartz T (2010) Creating the CIPRES Science Gateway for inference of large phylogenetic trees. Proceedings of the Gateway Computing Environments Workshop, New Orleans

Miller MR, Dunham JP, Amores A, Cresko WA, Johnson EA (2007) Rapid and cost-effective polymorphism identification and genotyping using restriction site associated DNA (RAD) markers. Genome Res 17:240-9248

Milne Edwards M, Haime J (1849) Recherches sur les polypiers; 4eme mémoire. Monographie des Astréides. Ann Sci Nat 3:95-197

Nishihira M, Veron JEN (1995) Hermatypic Corals of Japan. Kaiyusha, Tokyo

Obura DO (2012) The diversity and biogeography of Western Indian Ocean reef-building corals. PloS ONE 7:e45013 
Obura DO (2016) An Indian Ocean centre of origin revisited: Palaeogene and Neogene influences defining a biogeographic realm. J Biogeogr 43:229-242

Pante E, Abdelkrim J, Viricel A, Gey D, France SC, Boisselier MC, Samadi S (2015) Use of RAD sequencing for delimiting species. Heredity 114:450-459

Paz-García DA, Hellberg ME, García-de-León FJ, Balart EF (2015) Switch between morphospecies of Pocillopora corals. Amer Nat 186:434-440

Pinzón JH, Sampayo E, Cox E, Chauka LJ, Chen CA, Voolstra CR, LaJeunesse TC (2013) Blind to morphology: genetics identifies several widespread ecologically common species and few endemics among Indo-Pacific cauliflower corals (Pocillopora, Scleractinia). J Biogeogr 40:1595-1608

Prada C, DeBiasse MB, Neigel JE, Yednock B, Stake JL, Forsman ZH, Baums IB, Hellberg ME (2014) Genetic species delineation among branching Caribbean Porites corals. Coral Reefs 33:1019-1030

Pratchett MS, Caballes CF. Wilmes JC, Matthews S, Mellin C. Sweatman H, Nadler LE, Brodie J, Thmpson CA. Hoey J, Bos AR, Byrne M, Messmer V, Fortunato SA, Chen CCM, Buck ACE, Barbcok RC, Uthicke S (2017) Thirty years of research on crown-of-thorns starfish (1986-2016): scientific advances and emerging opportunities. Diversity 9:41

Puritz JB, Hollenbeck CM, Gold JR (2014) dDocent: a RADseq, variant-calling pipeline designed for population genomics of non-model organisms. PeerJ 2:e431

Quattrini AM, Wu T, Soong K, Jeng MS, Benayahu Y, McFadden CS (2019) A next generation approach to species delimitation reveals the role of hybridization in a cryptic species complex of corals. BMC Evol Biol 19:116

Quinlan AR, Hall IM (2010) BEDTools: a flexible suite of utilities for comparing genomic features. Bioinformatics 26:841-842

Rambaut A, Drummond AJ, Xie D, Baele G, Suchard MA (2018) Posterior summarization in Bayesian phylogenetics using Tracer 1.7. Syst Biol 67:901-904

Rancilhac L, Goudarzi F, Gehara M, Hemami MR, Elmer KR, Vences M, Steinfarz S (2019) Phylogeny and species delimitation of near Eastern Neurergus newts (Salamandridae) based on genome-wide RADseq data analysis. Mol Phylogenet Evol 133:1890-1897

Richards ZT, Berry O, Van Oppen MJ (2016) Cryptic genetic divergence within threatened species of Acropora coral from the Indian and Pacific Oceans. Conserv Genet 17:577-591

Roberts CM, McClean CJ, Veron JEN, Hawkins JP, Allen GR, McAllister DE, Mittermeier CG, Schueler FW, Spalding M, Weels F, Vynne C, Werner TB (2002) Marine biodiversity hotspots and conservation priorities for tropical reefs. Science 295:1280-1284

Rubin BE, Ree RH, Moreau CS (2012) Inferring phylogenies from RAD sequence data. PloS ONE 7:e33394

Rueden CT, Schindelin J, Hiner MC, DeZonia BE, Walter AE, Arena ET, Eliceiri KW (2017) ImageJ2: ImageJ for the next generation of scientific image data. BMC Bioinformatics 18:529

Sanderson MJ, Driskell AC, Ree RH, Eulenstein O, Langley S (2003) Obtaining maximal concatenated phylogenetic data sets from large sequence databases. Mol Biol Evol 20:1036-1042

Sargent TD, Jamrich M, Dawid IB (1986) Cell interactions and the control of gene activity during early development of Xenopus laevis. Dev Biol 114:238-246

Scheer G, Pillai CSG (1974) Report on the Scleractinia from the Nicobar Islands. Zoologica 42:1-198

Scheer G, Pillai CSG (1983) Report on the stony corals from the Red Sea. Zoologica 45:1-184

Schettino A, Turco E (2011) Tectonic history of the western Tethys since the Late Triassic. Geol Soc Am Bull 123:89105

Schmidt-Roach S, Miller KJ, Lundgren P, Andreakis N (2014) With eyes wide open: a revision of species within and closely related to the Pocillopora damicornis species complex (Scleractinia; Pocilloporidae) using morphology and genetics. Zool J Linnean Soc 170:1-33

Shearer TL, Van Oppen MJH, Romano SL, Wörheide G (2002). Slow mitochondrial DNA sequence evolution in the Anthozoa (Cnidaria). Mol Ecol 11:2475-2487

Sheppard CRC, Sheppard ALS (1991) Corals and coral communities of Saudi Arabia. Fauna of Arabia 12:1-170

Stamatakis A (2014) RAxML version 8: a tool for phylogenetic analysis and post-analysis of large phylogenies. Bioinformatics 30:1312-1313

Stefani F, Benzoni F, Yang SY, Pichon M, Galli P, Chen CA (2011) Comparison of morphological and genetic analyses reveals cryptic divergence and morphological plasticity in Stylophora (Cnidaria, Scleractinia). Coral Reefs 30:1033-1049

Stobie CS, Cunningham MJ, Oosthuizen CJ, Bloomer P (2019) Finding stories in noise: mitochondrial portraits from RAD data. Mol Ecol Resour 19:191-205 
Suchan T, Espíndola A, Rutschmann S, Emerson BC, Gori K, Dessimoz C, Arrigo N, Ronikier M, Alvarez N (2017) Assessing the potential of RAD-sequencing to resolve phylogenetic relationships within species radiations: the fly genus Chiastocheta (Diptera: Anthomyiidae) as a case study. Mol Phylogenet Evol 114:189-198

Terraneo TI, Berumen ML, Arrigoni R, Waheed Z, Bouwmeester J, Caragnano A, Stefani F, Benzoni F (2014) Pachyseris inattesa sp. n. (Cnidaria, Anthozoa, Scleractinia): a new reef coral species from the Red Sea and its phylogenetic relationships. ZooKeys 433:1-30

Terraneo TI, Benzoni F, Arrigoni R, Berumen ML (2016) Species delimitation in the coral genus Goniopora (Scleractinia, Poritidae) from the Saudi Arabian Red Sea. Mol Phylogenet Evol 102:278-294

Terraneo TI, Arrigoni R, Benzoni F, Forsman ZH, Berumen ML (2018a) Using ezRAD to reconstruct the complete mitochondrial genome of Porites fontanesii (Cnidaria: Scleractinia). Mitochondrial DNA B Resour 3:173-174

Terraneo TI, Arrigoni R, Benzoni F, Forsman ZH, Berumen ML (2018b) The complete mitochondrial genome of Porites harrisoni (Cnidaria: Scleractinia) obtained using next-generation sequencing. Mitochondrial DNA B Resour 3:286-287

Todd PA (2008) Morphological plasticity in scleractinian corals. Biol Rev 83:315-337

Toonen RJ, Puritz JB, Forsman ZH, Whitney JL, Fernandez-Silva I, Andrews KR, Bird CE (2013) ezRAD: a simplified method for genomic genotyping in non-model organisms. PeerJ 1:e203

Van Oppen MV, Willis BL, Vugt HV, Miller DJ (2000) Examination of species boundaries in the Acropora cervicornis group (Scleractinia, Cnidaria) using nuclear DNA sequence analyses. Mol Ecol 9:1363-1373

Vaughan TW (1918) Some shoal-water corals from Murray Islands, Cocos Keeling Islands ana Fanning Islands. Pap Dep Mar Biol Carnegie Inst Wash 9:51-234

Veron JEN, Pichon M, Wijsman-Best M (1977) Scleractinia of eastern Australia. Part. II. Families Faviidae, Trachyphylliidae. Australian Institute of Marine Science, Townsville

Veron JEN (2000) Corals of the World. Australian Institute of Marine Science, Townsville

Veron JEN (2002) New species described in corals of the world. Australian Institute of Marine Science, Townsville

Veron JEN, Stafford-Smith M, DeVantier L, Turak E (2015) Overview of distribution patterns of zooxanthellate Scleractinia. Front Mar Sci 1:81

Verrill A (1867) Synopsis of the polyps and corals of the North Pacific Exploring Expedition, with descriptions of some additional species from the West Coast of North America. III Madreporaria. Proc Essex Inst Salem 5:33-50

Vollmer SV, Palumbi SR (2004) Testing the utility of internally transcribed spacer sequences in coral phylogenetics. Mol Ecol 13:2763-2772

Wagner CE, Keller I, Wittwer S, Selz OM, Mwaiko S, Greuter L, Sivasundar A, Seehaunsen O (2013) Genome-wide RAD sequence data provide unprecedented resolution of species boundaries and relationships in the Lake Victoria cichlid adaptive radiation. Mol Ecol 22:787-798

Warner PA, Van Oppen MJ, Willis BL (2015) Unexpected cryptic species diversity in the widespread coral Seriatopora hystrix masks spatial-genetic patterns of connectivity. Mol Ecol 24:2993-3008

Wells JW (1956) Scleractinia. In: Moore RC (ed) Treatise on Invertebrate Paleontology, Part F. Geological Society of America, Boulder pp F328-F444

Wijsman-Best M (1980) Indo-Pacific coral species belonging to the subfamily Montastreinae Vaughan \& Wells, 1943 (Scleractinea - Coelenterata) Part II. The genera Cyphastrea, Leptastrea, Echinopora and Diploastrea. Zool Meded 55:235-263

Willis SC, Hollenbeck CM, Puritz JB, Gold JR, Portnoy DS (2017) Haplotyping RAD loci: an efficient method to filter paralogs and account for physical linkage. Mol Ecol Resour 17:955-965

Zhang J, Kobert K, Flouri T, Stamatakis A (2013) PEAR: a fast and accurate Illumina Paired-End reAd mergeR. Bioinformatics 30:614-620

\section{Figure legends}

Fig. 1 Skeleton morphology of the Leptastrea type specimens $(\mathbf{a}, \mathbf{e}, \mathbf{i}, \mathbf{m}, \mathbf{q})$ and material examined in this study (b-d, f-h, j-l, n-p, r-t): L. purpurea (Dana, 1846) (a USNM 75; b-d UNIMIB GA059), L. pruinosa Crossland, 1952 (e BMNH 1934.5.14.630, reproduction of the original illustration; f-h UNIMIB GA170), L. transversa Klunzinger, 1879 


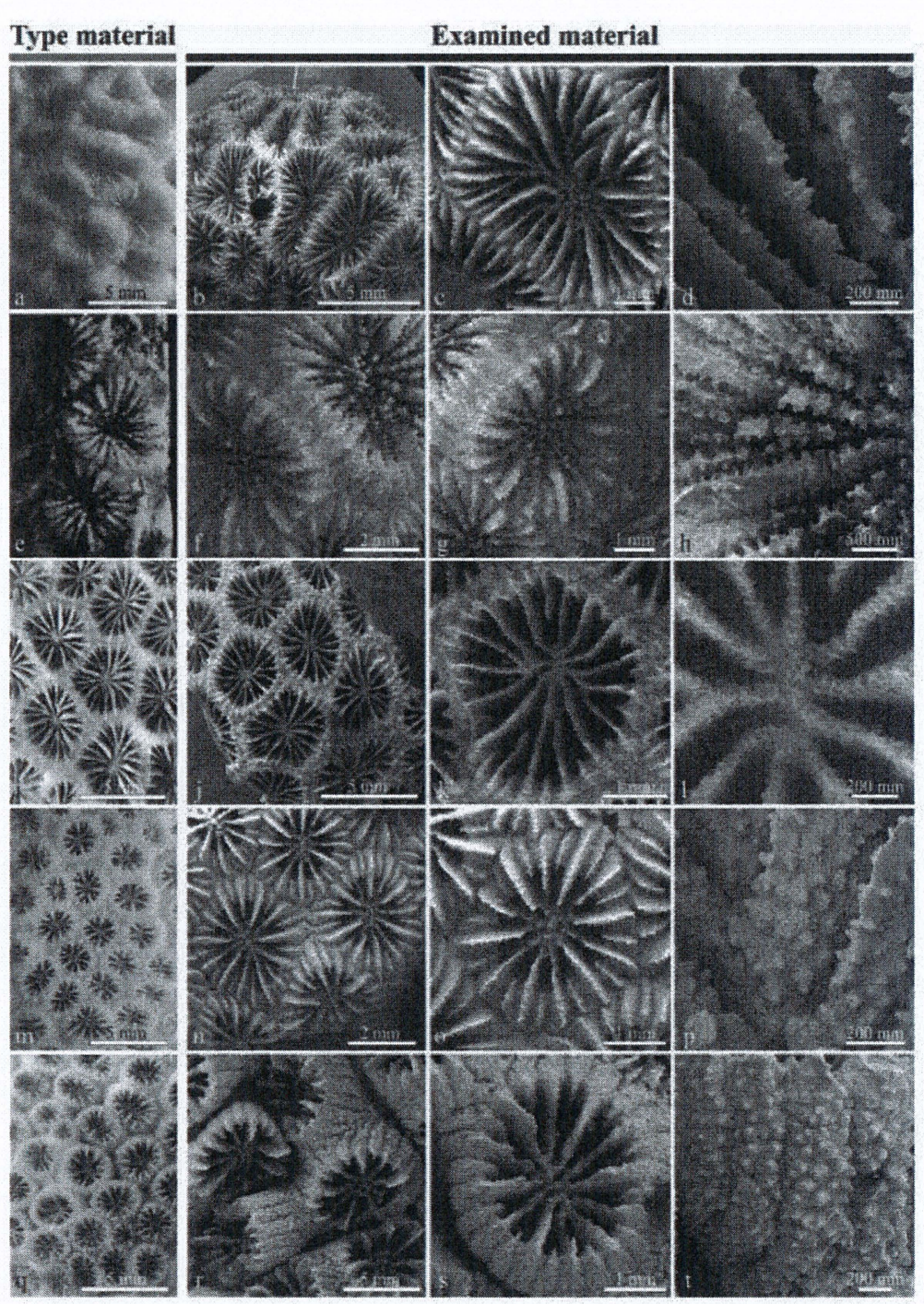

1092

Fig. 2 Leptastrea gibbosa sp. n.: a holotype MNHN-IK-2012-9823; b IRD HS2344 (black arrows indicates a giant

1094 corallite); $\mathbf{c}$ IRD HS3740; $\mathbf{d}$ and e corallite arrangement and the characteristic pits and grooves in UNIMIB PFB805 1095 and IRD HS3740, respectively; f longitudinal section of IRD HS3740 showing beam-like structures transversally 1096 joining adjacent corallite walls the corallite walls (black arrows) and their longitudinal section (outlined); g-l SEM 1097 images of a fragment of the holotype showing $\mathbf{g}$ detail of the pits among corallites, $\mathbf{h}$ a side view of the corallum 1098 surface and of the exsert septa, $\mathbf{i}$ the septa organized in two complete (S1-2) and one incomplete (S3) cycles, $\mathbf{j}$ the 1099 finely granulated costae, $\mathbf{k}$ the columella, and $\mathbf{l}$ a side view of the slightly undulating S1 and S2 

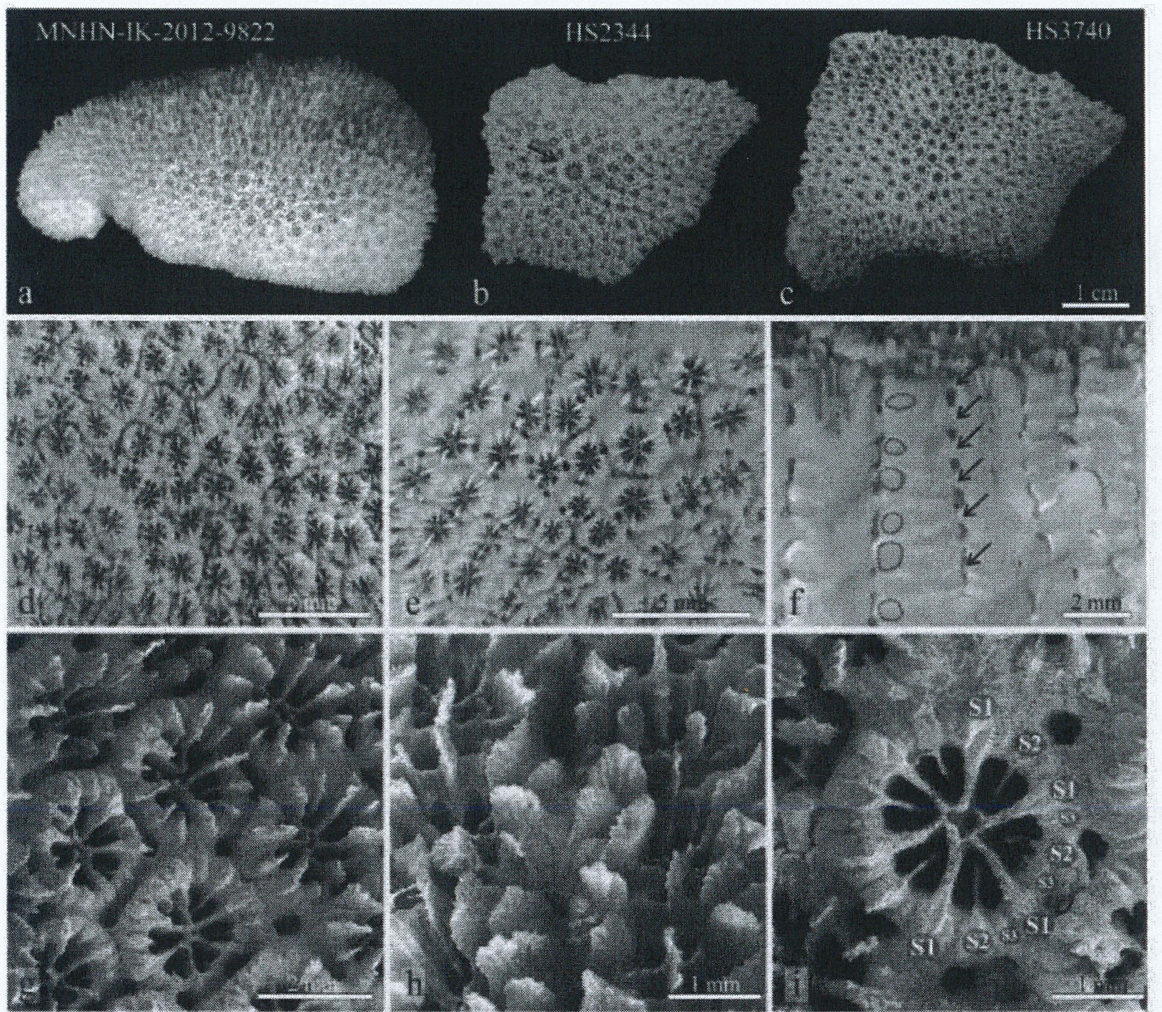

1100
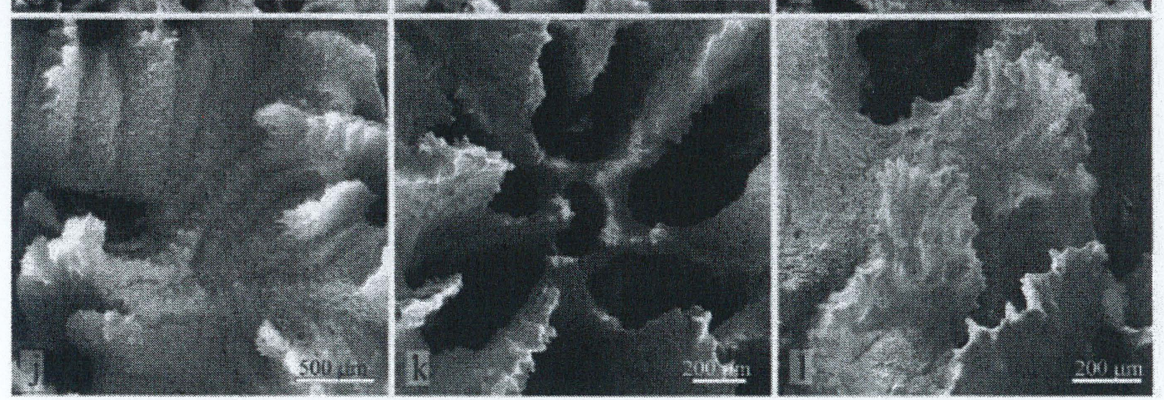

1101 Fig. 3 Leptastrea magaloni sp. n.: a holotype MNHN-IK-2012-9823; b) IRD MD183, the arrow points at

1102 extratentacular budding; c IRD MD225; corallites of $\mathbf{d}$ the holotype, the arrow points at intratentacular budding, $\mathbf{e}$

1103 IRD MD222, f IRD MD274; $\mathbf{g}$ IRD MD260; h-l SEM images of a fragment of the holotype showing $\mathbf{h}$ plocoid

1104 corallites, $\mathbf{i}$ side view of a corallite and its columella composed of multiple processes, $\mathbf{j}$ the finely granulated costae,

$1105 \mathbf{k}$ the septa organized in three complete (S1-4) cycles (arrows point at paddle-shaped structures at the proximal end of

1106 S3), and $\mathbf{I}$ a side view of S1 and S2 


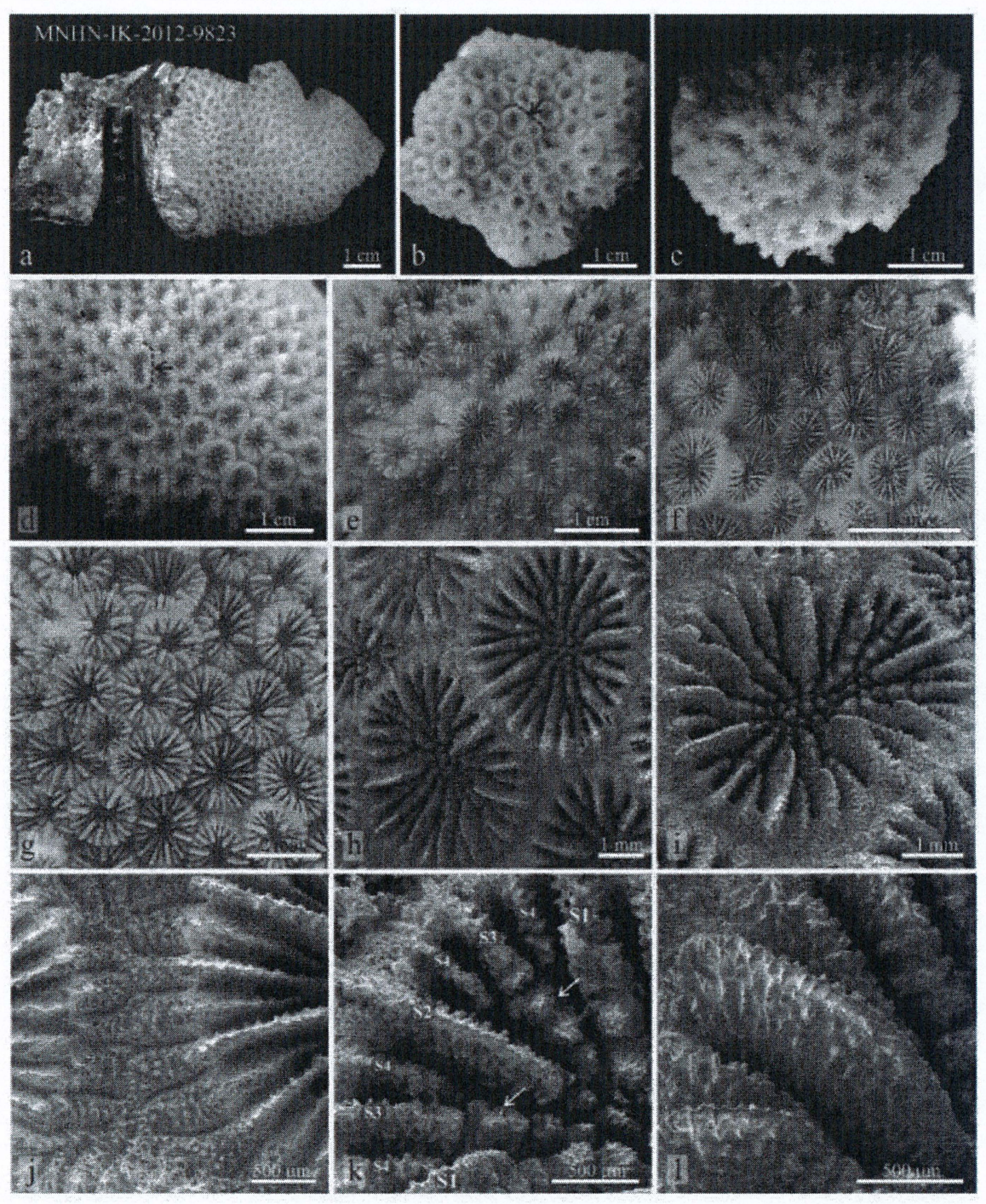

1108 Fig. 4 Maximum Likelihood (ML) phylogenetic tree of Leptastrea estimated with RAxML v8.2.10 using a the

1109 concatenated "holobiont-max" supermatrix (3,701 loci including a total of 44,162 SNPs); b the concatenated "coral-

1110 max" supermatrix (9,573 loci including a total of 62,728 SNPs). Branch support is based on ML bootstrap analyses $\geq$

111150 (first number at node) and Bayesian posterior probabilities $\geq 0.5$ (second number at node) 
a)

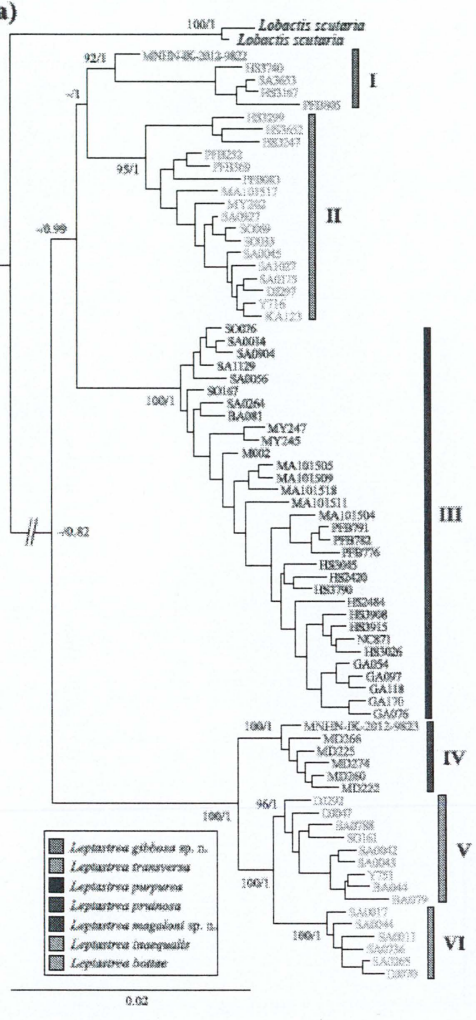

b)

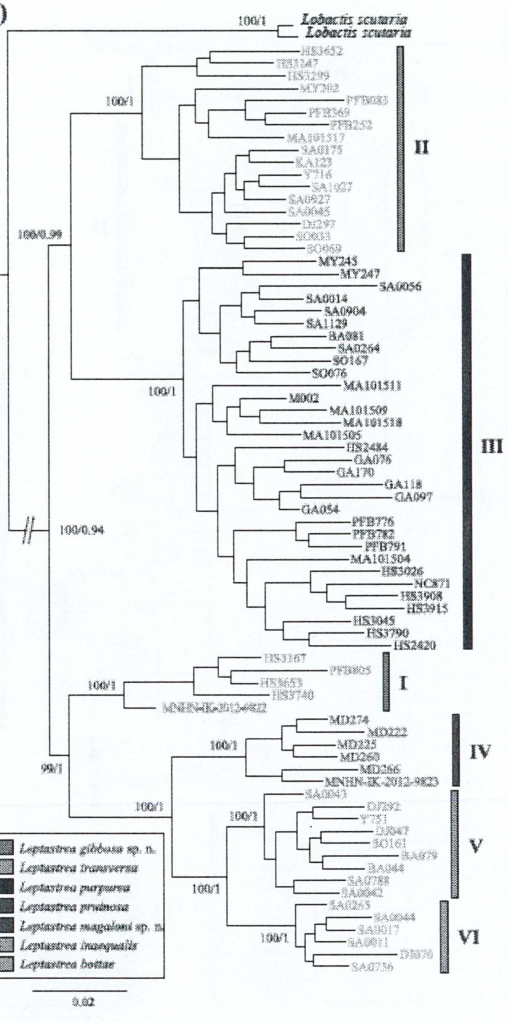

1113 Fig. 5 Maximum Likelihood (ML) phylogenetic tree of Leptastrea estimated with RAxML v8.2.10 using a nearly 1114 complete coral mitochondrial genomes (10,837 bp); b nearly complete nuclear ribosomal DNA arrays $(5,835$ bp).

1115 Branch support is based on ML bootstrap analyses $\geq 50$ (first number at node) and Bayesian posterior probabilities $\geq$ 0.5 (second number at node) 


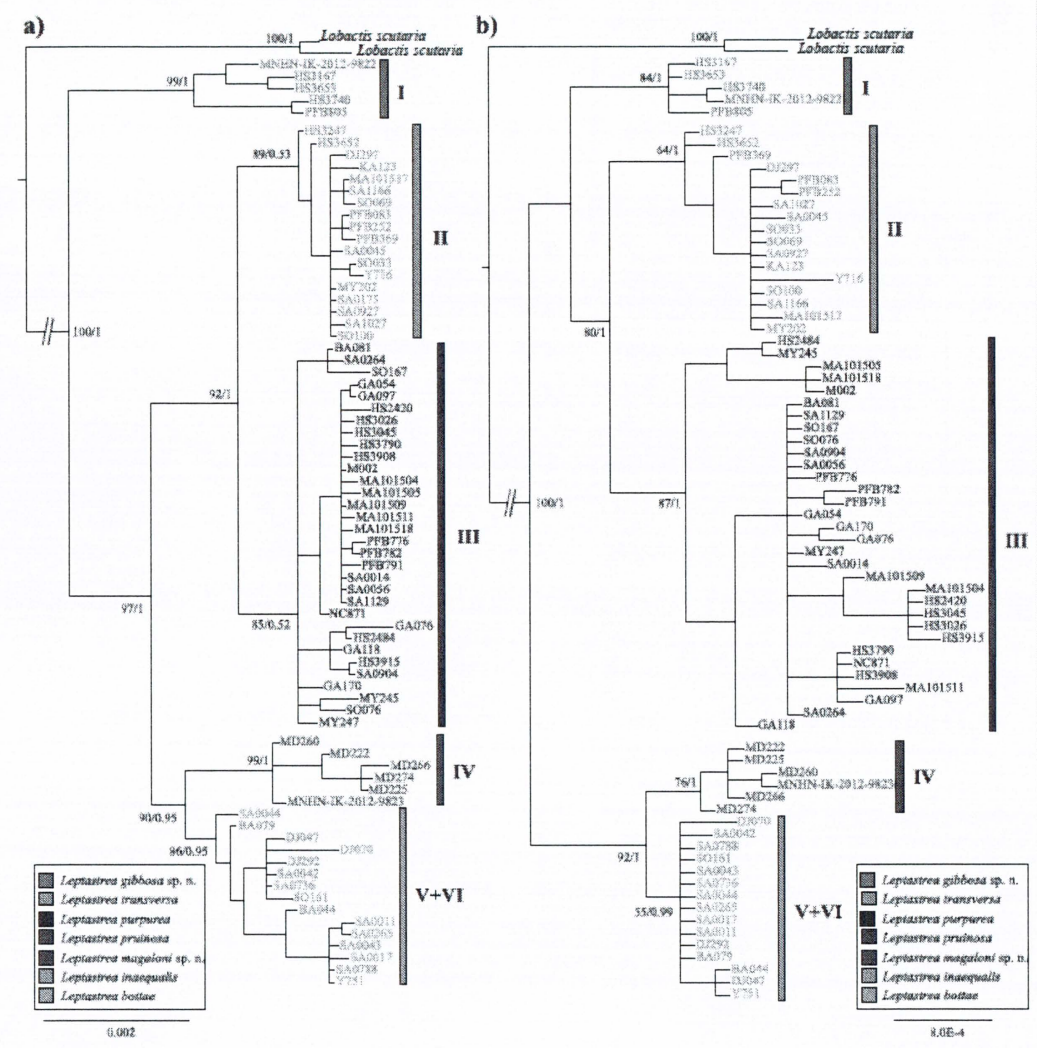

1118 Fig. 6 Species tree estimation of Leptastrea based on 1,857 unlinked biallelic SNPs with 0\% missing data inferred 1119 from SNAPP, following the best-supported model from the Bayes Factor Delimitation with genomic data (BFD*) 1120 analysis shown in Table 1. a complete set of consensus trees visualized with DensiTree; $\mathbf{b}$ distribution maps of each 1121 species. Circles denote specimens analyzed in this study, squares specimens deposited at museum collections that we 1122 identified based on our newly proposed morphological treatment, stars type locality 
a)

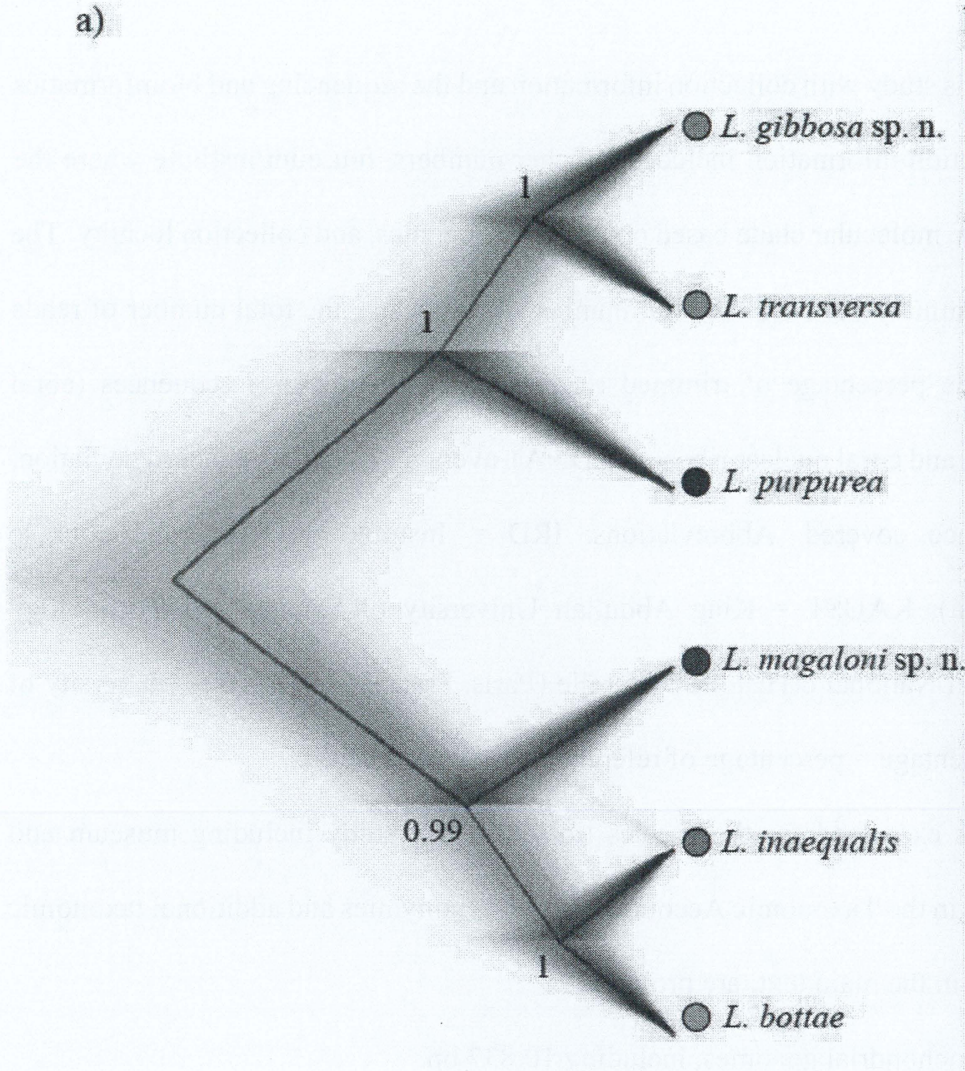

b)

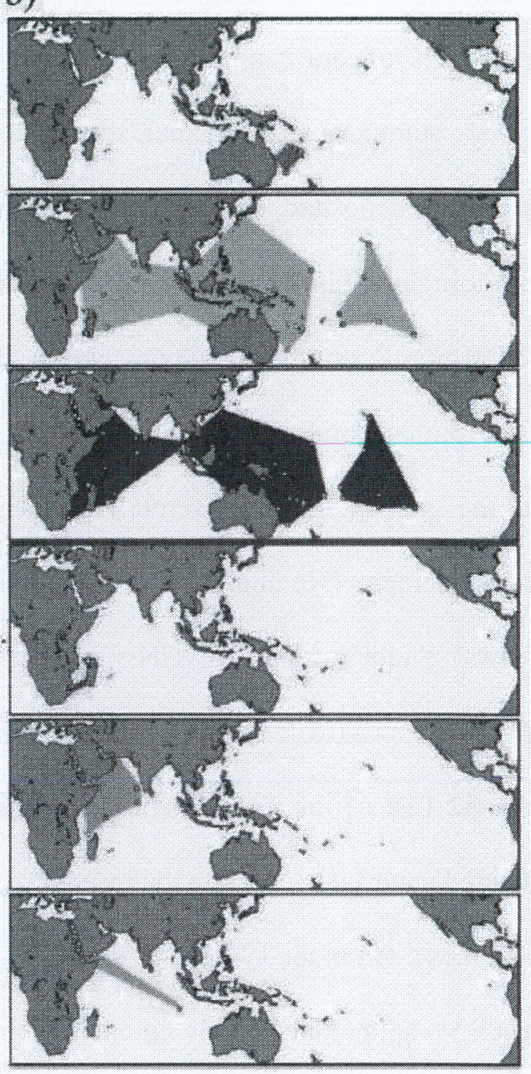

1124 Fig. 7 Plot of the first two principal components (PC) analyses of all examined Leptastrea specimens including

1125 holotypes (star symbols), showing the ordination of the specimens based on corallite morphometric variables. Each

1126 symbol represents a specimen (average of 5 replicates). Groups of specimens of the same species are enclosed by

1127 dashed polygon. Corresponding genetic clade in parenthesis as per Fig. 4. Color code is the same as in Figs. 4-6

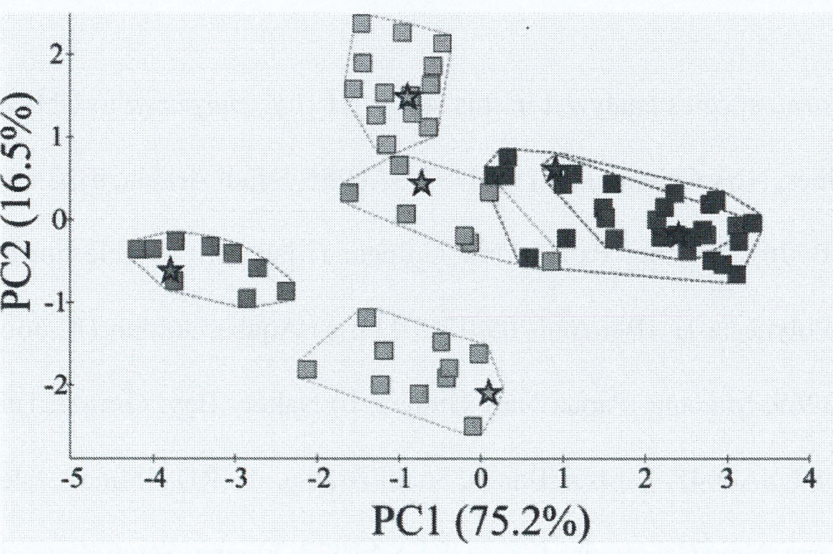

- Leptastrea gibbosa sp. n. (I)

$\square$ Leptastrea transversa (II)

- Leptastrea purpurea (III)

- Leptastrea magaloni sp. n. (IV)

$\square$ Leptastrea inaequalis (V)

- Leptastrea bottae (VI)

$\star$ Type specimen 
1131 Data S1 List of coral samples analyzed in this study with collection information and the sequencing and bioinformatics

1132 statistics summary. In particular, the collection information includes voucher numbers, museum/institute where the

1133 specimen is deposited, species identification, molecular clade based on SNPs phylogenies, and collection locality. The

1134 sequencing and bioinformatics statistics summary includes the total number of raw reads, the total number of reads

1135 after trimming and relative percentage, the percentage of trimmed reads mapped to reference sequences (coral

1136 transcriptome, coral mitochondrial genome, and coral nuclear ribosomal DNA), average deviation, standard deviation,

1137 and the percentage of reference sequence covered. Abbreviations: IRD = Institute de Recherche pour le

1138 Développement (Noumea, New Caledonia); KAUST = King Abdullah University of Science and Technology

1139 (Thuwal, Saudi Arabia); MNHN = Muséum National d'Histoire Naturelle (Paris, France); UNIMIB = University of

1140 Milano-Bicocca (Milan, Italy); refseq percentage = percentage of reference sequence covered.

1141 Data S2 List of the Leptastrea specimens examined for the species treated in this study including museum and

1142 collected material in addition to those listed in the Taxonomic Account. Species synonymies and additional taxonomic

1143 references cited in the synonymies, but not in the main text, are provided.

1144 Data S3 Alignment of nearly complete mitochondrial genomes, including 10,837 bp.

1145 Data S4 Alignment of nearly complete nuclear ribosomal DNA regions, including 5,835 bp.

1146 Data S5 Average (st. dev.) values of the six Leptastrea skeleton variables measured in this study: v1, maximum calice

1147 diameter; v2, minimum calice diameter; v3, maximum columella diameter; v4, minimum columella diameter 1148 perpendicular to v3; v5, distance between the centre of the columella and the centre of the columella of the closest 1149 adjacent corallite; v6, width of the groove among the corallites. The number of coralla examined per species is given 1150 in brackets below the species name.

1151 Figure S1 In situ images of colonies of the Leptastrea species analyzed in this study: S1_1 L. purpurea a) UNIMIB 1152 MY143, Mayotte Island; b) IRD HS3790, Isle of Pines, New Caledonia; c) KAUST SA0056, Saudi Arabia; d) KAUST

1153 SA0014, Al Lith, Saudi Arabia; e) UNIMIB PFB776, Kavieng, Papua New Guinea; f) lagoon pinnacle north of 1154 Magareva Island, Gambier Archipelago, French Polynesia (F. Benzoni, 05/07/2011); g) Aqaba, Jordan (R. Joury, 1155 17/07/2018); S1_2 L. transversa a) UNIMIB PFB369, Madang, Papua New Guinea; b) Nakety Bay, Grande Terre, 1156 New Caledonia (F. Benzoni, 22/04/2012); c) KAUST SA0045, Farasan Banks, Saudi Arabia; d) IRD HS3652, Isle of 1157 Pines, New Caledonia; e) IRD HS3299, Grande Terre, New Caledonia; f) KAUST SA1027, Magna, Saudi Arabia; g) 

SA0011, Al Lith, Saudi Arabia; c) Aqaba, Jordan (F. Benzoni, 09/07/2018); d) KAUST SA0044, Farasan Banks,

1160 Saudi Arabia; e) UNIMIB DJ070, Oblal, Djibouti; f) KAUST SA0011, Al Lith, Saudi Arabia; g) Aqaba, Jordan (R. Joury, 16/07/2018); S1_4 L. inaequalis a) UNIMIB BA079, Bir Ali, Yemen; b) UNIMIB DJ047, Oblal, Djibouti; c) Aqaba, Jordan (F. Benzoni, 15/07/2018); d) KAUST SA0043, Farasan Banks, Saudi Arabia; e) KAUST SA0042, Farasan Banks, Saudi Arabia; f) Socotra Island, Yemen (F. Benzoni, 18/03/2010); g) Aqaba, Jordan (R. Joury, 16/07/2018); S1_5 Leptastrea gibbosa sp. n. a) Lifou Island, Loyalty Islands, New Caledonia (F. Benzoni, 18/02/2014); b) outer reef south of the Grande Terre, New Caledonia (F. Benzoni, 08/11/2017); c) IRD HS3167, Moneo, Grande Terre, New Caledonia; d) UNIMIB PFB805, Kavieng, Papua New Guinea; e) IRD HS3740, Isle of Pines, New Caledonia; f) IRD HS3653, Isle of Pines, New Caledonia ; g) Mellish Reef, Australia (F. Benzoni, 02/12/2018); S1_6 Leptastrea magaloni sp. n. a) IRD MD266, Nosy Sakatia, Madagascar; b) IRD MD260, Nosy Be, Madagascar; c) IRD MD222, Nosy Lava, Madagascar; d) MNHN-IK-2012-9823, Bouzi, Mayotte Island; e) IRD MD225, Nosy Lava, Madagascar; f) IRD MD183, Nosy Mitsio, Madagascar; g) IRD MD274, Nosy Sakatia,

1171 Madagascar; h) same colony as in g with retracted tentacles. All in situ specimen images by F. Benzoni. For specimens, site and date metadata can be found in Data S1.

1173 Figure S2 Maximum Likelihood (ML) phylogenetic tree of Leptastrea estimated with RAxML v8.2.10 using a) the 1174 concatenated "holobiont-min" supermatrix (2,075 loci including a total of 2,141 SNPs); b) the concatenated "coral1175 min" supermatrix (2,366 loci including a total of 2,479 SNPs). Branch support is based on ML bootstrap analyses.

1176 Figure S3 Maximum Likelihood (ML) phylogenetic tree of Leptastrea estimated with RAxML v8.2.10 using a) the 1177 barcoding portion of the cytochrome oxidase subunit I gene of the mitochondrial genome (COI); b) the complete ITS1, 1178 5.8S, and ITS2 regions of the nuclear ribosomal DNA (ITS). Branch support is based on ML bootstrap analyses.

1179 Figure S4 Variability of skeleton morphology across specimens of the Leptastrea species examined in this study 1180 included in the genomic and morphometric analyses: L. purpurea (a-h), L. transversa (i-1), L. gibbosa sp. n. (m-p), L. 1181 inaequalis (q-t), L. bottae (u-x), L. magaloni sp. n. (y-ab). a) UNIMIB BA081; b) UNIMIB MY247; c) UNIMIB 1182 MY245; d) IRD HS3045; e) UNIMIB PFB776; f) UNIMIB GA097; g) UNIMIB GA170; h) UNIMIB GA076; i) UNIMIB DJ297; j) UNIMIB MY202; k) UNIMIB PFB252; l) IRD HS3247; m) UNIMIB PFB805; n) IRD HS3740; o and p) IRD HS2344; q) UNIMIB DJ292; r) UNIMIB BA044; s) UNIMIB BA079; t) UNIMIB DJ047; u) UNIMIB AD040; v) UNIMIB DJ070; w) UNIMIB BAL144; x) UNIMIB DJ335; y) UNIMIB MY333; z) IRD MD260; aa) IRD 
1186 MD183; ab) IRD MD222. All images were taken at the same magnification (scale bar shown in a). Colour code same

1187 as in Figures 4-7. Collection metadata for L. magaloni sp. n. and L. gibbosa sp. n. specimens are in the Taxonomic 1188 Account, for all the other species in Data S1. 